\title{
Novel Process for the exergetically efficient recycling of chlorine by gas phase electrolysis of hydrogen chloride
}

\author{
Simon Bechtel ${ }^{\mathrm{a}}$, Tanja Vidakovic-Koch ${ }^{\mathrm{a}}$, Kai Sundmacher ${ }^{\mathrm{a}, \mathrm{b}, *}$ \\ ${ }^{a}$ Max Planck Institute for Dynamics of Complex Technical Systems, Department \\ Process Systems Engineering, Sandtorstr.1, D-39106 Magdeburg, Germany \\ ${ }^{\mathrm{b}}$ Otto-von-Guericke- University Magdeburg, Department Process Systems \\ Engineering, Universitätsplatz 2, D-39106 Magdeburg, Germany \\ * Corresponding author: Sundmacher@mpi-magdeburg.mpg.de
}

\begin{abstract}
Due to the steadily increasing production capacities of polycarbonates and polyurethanes, the volume of hydrogen chloride $(\mathrm{HCl})$, which emerges as byproduct from these processes, is experiencing a significant growth. Owing to the oversaturation of the market for $\mathrm{HCl}$ and hydrochloric acid, the question on how to utilize this byproduct in a sustainable and energyefficient way is becoming more and more important. The oxidation of $\mathrm{HCl}$ to chlorine, which can be redirected as an educt to these above mentioned processes, offers a feasible solution to this problem and can be carried out either heterogeneously catalyzed at high temperatures or through electrolysis. Up to now, the most energy-efficient industrially employed electrochemical variant is the Bayer UHDENORA process, based on aqueous hydrochloric acid as a feed stock. The major objective of this work is to propose a novel electrochemical process utilizing $\mathrm{HCl}$ as a gaseous reactor feed in order to significantly reduce the electrical energy demand of the reactor combined with new and more energy-efficient subsequent separation sequences. For this purpose, flowsheet simulations of the Bayer UHDENORA process and two novel process variants based on the gas phase reactor and two different separation sequences were carried out
\end{abstract}


and followed by a detailed exergy analysis. The analysis shows significant exergetic savings of up to $38 \%$ in this novel process variants compared to the Bayer UHDENORA process, including not only the electrochemical reactor but also the subsequent separation steps. The novel process therefore allows for a more sustainable and energy-efficient production of the base chemical chlorine and, contrary to the heterogeneously catalyzed high temperature process, for the utilization of electrical energy from advancing renewable sources like wind and sun.

\section{Keywords}

Energy-Efficient $\mathrm{HCl}$ Recycling, Gas Phase Electrolysis, Exergy Analysis, Process Simulation, Chlorine

\section{Introduction}

Chlorine is a base chemical with a production capacity of 66 million tons worldwide in 2014 and an expected increase to up to 76 million tons per year until 2019 [1]. Most of the chlorine is produced through the electrolysis of sodium chloride. The average electrolysis plant of that kind has an energy demand of 3.3 MWh per ton of chlorine which leads to an overall energy consumption of more than 200000 GWh every year worldwide [2]. Chlorine is widely used in the production of plastics, sanitary and medical products as well as organic solvents and mostly stems from the chlor-alkali electrolysis [3,4]. Interestingly, one third of all substances produced with the aid of chlorine do not contain $\mathrm{Cl}_{2}$ themselves and $50 \%$ of the employed chlorine is being discharged in form of side products like hydrogen chloride or chloride salts [5]. Great example processes with a further growing industrial relevance are the isocyanate and polycarbonate production [5]. The volume of polycarbonates has been 3.7 million metric tons in 
2013 and is predicted to rise by $5 \%$ until 2018 [5]. The most important isocyanate is methylen diisocyanate (MDI) with a production capacity of 4.6 million tons in 2011 and a growth rate of 5\%, followed by toluene diisocyanate (TDI) with a production volume of 3 million tons in 2013 $[3,7,8]$. Both, the isocyanate and polycarbonate production employ phosgene as a reactant which is synthesized from chlorine and carbon monoxide. Therefore, for each mole of TDI and MDI, two moles of chlorine are consumed and four moles of hydrogen chloride emerge as a byproduct. Since processes that consume hydrogen chloride, like the production of PVC, are growing at a much slower rate, the market for this byproduct is over-saturated [4,5]. This is where the electrochemical or heterogeneously catalyzed conversion of hydrogen chloride to chlorine comes into play.

The heterogeneously catalyzed conversion of $\mathrm{HCl}$ to chlorine based on the Deacon process and its predecessors like the Shell or Mitsui process has been described in detail by Ramirez et al. [5]. In general, the heterogeneously catalyzed process has the advantage of a significantly lower energy demand and therefore lower production costs. This is due to the fact that the electrochemical alternative requires a significant amount of electrical energy in order to reach industrially relevant current densities of 3-4 $\mathrm{kA} \mathrm{m}^{-2}$ [4,5]. However, the investment costs of the electrochemical processes are markedly lower. Furthermore, the modularity of the electrochemical variant allows for a flexible production capacity and easy scalability which makes it very attractive in small scale plants or in a volatile economic setting [4,5]. Especially in the context of the current transition from fossil fuels to renewable energy sources, the electrolysis of $\mathrm{HCl}$ allows for employing the electricity stemming from these renewable sources for a green and sustainable production of chlorine as shown in Fig.1. Additionally, not only does 
the electrolysis of $\mathrm{HCl}$ allow for a sustainable chlorine recycling, it also consumes four times less energy compared to the production of chlorine trough the electrolysis of sodium chloride, as will be shown in this work. Therefore, the focus of this work is on the electrochemical process variants and the proposal as well as the exergetic assessment of two novel processes based on the oxidation of gaseous hydrogen chloride forming water and chlorine.

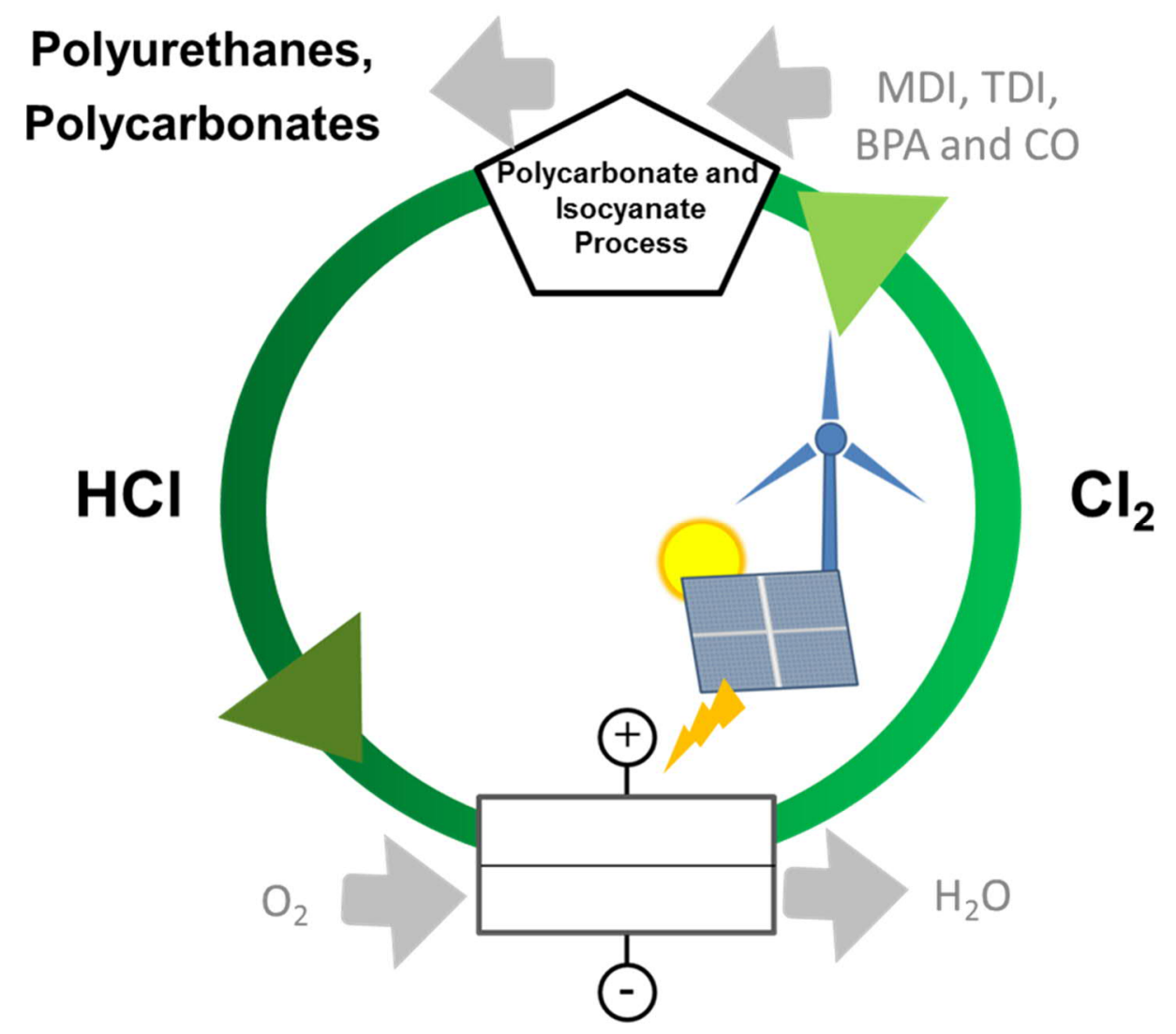

Fig. 1 Scheme for the utilization of renewable energy sources for the recycle of hydrogen chloride to chlorine which then again enters into main industrial processes like the polyurethane and polycarbonate production.

The first industrially employed electrochemical process was developed by Hoechst, Bayer and Uhde in the 1960s, deploying the diaphragm electrolyzer technology. A more recent variant from Bayer and UHDENORA is based on the membrane electrolyzer technology employing an 
oxygen depolarized cathode, which leads to energy savings of up to $30 \%$ [4,5,7]. In addition to these processes, which both utilize aqueous hydrochloric acid as a feed stream, DuPont has developed a gas phase process in which hydrogen chloride is split to hydrogen and chlorine. Besides the establishment of a pilot scale unit in 1995, this process has never been industrially commercialized $[5,9]$.

Recently, our group has reported on a new electrochemical gas phase reactor for hydrogen chlorine electrolysis with oxygen depolarized cathode from now on just labeled as "gas phase reactor") in cooperation with TU Clausthal [4,12]. With an energy consumption of only $730 \mathrm{kWh}$ per ton of chlorine, equivalent to a cell potential of $0.977 \mathrm{~V}$ at $4 \mathrm{kA} \mathrm{m}^{-2}$, this reactor allows for power savings of $31.5 \%$ compared to the liquid phase electrochemical reactor of the Bayer UHDENORA process, which has an energy demand of $1070 \mathrm{kWh}$ per ton of chlorine $[4,12]$. Additionally, the heat discharge in the gas phase reactor, and therefore also its exergetic portion, is markedly higher compared to the liquid phase reactor in the state-of-the-art process due to the negative reaction entropy which leads to an additional exergetic advantage of the gas phase reactor. However, up to now, no separation sequences for the mixture of chlorine and gaseous hydrogen chloride leaving the electrochemical reactor have been proposed. Having in mind that the overall efficiency of the process is influenced not only by the reactor but also by separation steps, a main aim of this study is to determine, whether the significant exergetic advantage of the electrochemical gas phase reactor can be maintained at the process level after including all necessary separation steps. This would allow for a more energy- and cost-efficient as well as ecological production of the important base chemical chlorine. For this reason two new separation strategies for the electrochemical gas phase reactor with an oxygen depolarized 
cathode were developed and analyzed. As a benchmark for evaluating their performance, the currently most energy-efficient industrially employed process from Bayer and UHDENORA was chosen.

In order to compare the two proposed novel gas phase processes with the state-of-the-art method, all of them, including the separation and purification steps, were simulated with Aspen Plus and a detailed exergy analysis was carried out for all processes. Hereby, the two novel processes both utilize the same gas phase reactor but different separation sequences.

\section{Methods}

\subsection{Simulation of the state-of-the-art process and the proposed novel gas phase processes}

In the present work, the sequential modular approach of the process simulation software Aspen Plus was applied $[13,14]$. Firstly, the state-of-the-art process was simulated utilizing parameters given in literature as summarized in Table 1. Secondly, the two novel process variants were simulated as well. Since the energy and exergy demand strongly depend on the amount of converted hydrogen chloride, the overall conversion must be identical in all of the five simulations to ensure comparability. Therefore, an overall conversion of $80 \%$ was arbitrarily

chosen. The $20 \%$ of hydrogen chloride that are not converted were dissolved in water, forming concentrated hydrochloric acid $(37 \mathrm{wt} \%)$ in all processes. This is supposed to reproduce an economically realistic scenario where a significant part of the hydrogen chloride is converted to chlorine and the rest is either reused within the Verbund in the form of concentrated acid or sold. Of course, this arbitrary ratio of $80: 20$ should and can be adjusted to the specific economic 
situation which is dependent on a variety of individual parameters, like the actual market price of $\mathrm{HCl}$, the geographical location of the site or the Verbund-internal demand of hydrochloric acid. A further advantage of choosing a fixed overall conversion is that all the inlet and outlet streams, with exception for waste streams and auxiliary substances, are identical and therefore dispose of the same exergy. This is due to the fact that in all of the following simulations, every stream is entering and leaving the system at atmospheric pressure and a temperature of $298.15 \mathrm{~K}$. Therefore, if waste and auxiliary streams are negligibly small, only the exergy of the supplied and discharged heat and electricity is relevant for comparing the exergy demand of the five process variants and the laborious task of calculating the exergy of all the substance streams becomes no longer necessary. The waste streams as well as the feed streams for auxiliary substances in the present work are indeed negligibly small so that the above assumption is justified.

Additionally, five more simulations with a total conversion of 15, 30, 45, 60 and $70 \%$ for both of the novel process variants have been carried out and included in the exergy analysis to determine which conversion leads to the lowest exergy demand per $\mathrm{kg}$ of generated chlorine and to investigate whether one of the two processes becomes more feasible than the other one in a certain conversion regime. All simulated processes are designed for a hydrogen chloride feed stream of $375 \mathrm{kt}$ per year resulting in a molar feed flow rate of $0.362 \mathrm{kmol} \mathrm{s}^{-1}$ assuming an uptime of 8000 hours per year. This data is based on an MDI production site from BASF in Antwerp with a capacity of $650 \mathrm{kt} \mathrm{a}^{-1}$ [15]. The oxygen feed stream was chosen to be $0.09 \mathrm{kmol} \mathrm{s}^{-1}$ which is approximately the stochiometrically necessary amount for converting all of the fed hydrogen chloride. Again, it is necessary to choose a common value for all processes 
for reasons of comparability. The exact amount of excess oxygen is irrelevant at this point of the study and can be adjusted when the most efficient process variant has been found. The minimum purity of chlorine was set to $99.5 \mathrm{wt} \%$ based on the grade 2.5 sold by Linde [16]. The maximum amount of water in the chlorine product stream was limited to $100 \mathrm{ppm}\left(\mathrm{mg} \mathrm{kg}^{-1}\right)$ water [17].

\subsection{State-of-the-art process}

This process was modeled based on information from UHDENORA [6], the work of Ramirez et al. [5], and the patent by Ooms et al. [17]. All essential data are listed in Table 1.

\begin{tabular}{ll}
\hline Reactor temperature & $55{ }^{\circ} \mathrm{C}$ \\
\hline Power consumption of the reactor & $1070 \mathrm{kWh}$ per ton chlorine \\
Current density & $\mathrm{Up}$ to $5 \mathrm{kA} \mathrm{m}{ }^{-2}$ \\
Hydrochloric acid reactor feed concentration & $14 \mathrm{wt} \%$ \\
Hydrochloric acid reactor outlet concentration & $11 \mathrm{wt} \%$ \\
Temperature hydrogen chloride absorber & $35{ }^{\circ} \mathrm{C}$ \\
Concentration of hydrochloric acid product stream & $37 \mathrm{wt} \%$ \\
\hline
\end{tabular}

Table 1 Technical data and process conditions of the Bayer UHDENORA process [7,15].

According to the data given by UHDENORA, the concentration of the hydrochloric acid in the inlet stream of the reactor was chosen to be $14 \%$ [7]. The outlet concentration is not specified by this source. Therefore, the lower limit of $11 \%$ stated in the work of Ooms et al. [17] was chosen. Trainham et al. [18] have explained that in the Uhde process, the hydrochloric acid concentration 
has to be lower than $22 \%$ in order to avoid a drop in the conductivity and higher than $17 \%$ to prevent oxygen formation in the anode chamber. Similar reasoning also holds for the Bayer UHDENORA process which explains the tight concentration interval leading to a maximum achievable single pass conversion of $22.9 \%[6,17]$. In order to reduce the size of the recycle streams, which should have a positive impact on the energy amount required in the distillation unit and the investment costs due to smaller apparatus sizes, this maximum value of $22.9 \%$ was chosen for the simulation. While in the basic flowsheet from UHDENORA [7] it seems that the dechlorination takes part after the newly incoming hydrochloric acid is mixed with the reactor outlet stream, Ooms et al. [17] describe the dechlorination to follow directly after the reactor outlet. The latter variant will be more energy-efficient because the chlorine has to be separated in a distillation column. The heat duty of this unit would be significantly higher if the newly incoming hydrochloric acid is added to the feed of the column instead of after the separation. Therefore, the more energy-efficient variant based on the work of Ooms et al. [17] is chosen in this simulation.

Fig. 2 shows the process flow diagram for the state-of-the-art process. The split marked in red divides the dilute hydrochloric acid stream into two sub-streams that are used for the absorption of the incoming hydrogen chloride and the dilution of the generated concentrated hydrochloric acid towards the reactor inlet concentration. From the chloride ion mass balance follows that a split fraction of $9.88 \%$ of the incoming mass flow is directed towards the absorption step. However, the stoichiometric reactor model in Aspen Plus does not allow for directly separating the anode and cathode streams. Therefore, in a consecutive separator, the water and oxygen in the reactor outlet stream are isolated from the hydrogen chloride and the emerged chlorine. This 
separator is only used as a tool in Aspen Plus to simulate separate anode and cathode outlet streams and is not needed in a real plant. Afterwards, the chlorine can be separated from the hydrochloric acid through distillation.

The column specifications have been adjusted in a way that the amount of water in the distillate is slightly below the maximal limit of $100 \mathrm{ppm}\left(\mathrm{mg} \mathrm{kg}^{-1}\right)$. Choosing values significantly lower than $100 \mathrm{ppm}$ leads to a decrease in the condenser temperature of the column, which is below ambient temperature, and increases the necessary reflux ratio. Both effects lead to a higher exergy demand of the column. For this reason the limiting value of $100 \mathrm{ppm}$ was fully exploited. However, in the work of Ooms et al. [17] and other articles as well as patents about the heterogeneously catalyzed high temperature process, the specified purity of the chlorine is achieved by drying it with concentrated sulfuric acid. The advantage is that the exergetic demand of the distillation column can be reduced since the purity requirements of the distillate are lowered. The disadvantage lies in the necessity of introducing sulfuric acid as an auxiliary component and the additional apparatus for drying the chlorine and for re-concentrating the sulfuric acid. Therefore, it would have to be determined which variant is the overall most efficient one. To not needlessly overcomplicate the comparability of all the simulated processes in this work, they have been designed in a way that the distillation of chlorine yields a sufficient purity so that no drying with sulfuric acid is required. In order for the process simulation to abide the given constraints like purity and size of the product and purge streams, several design specifications and optimizations have been implemented into the simulation in order to control the concentration of the reactor feed stream and to reduce the heat duty of the distillation column. 


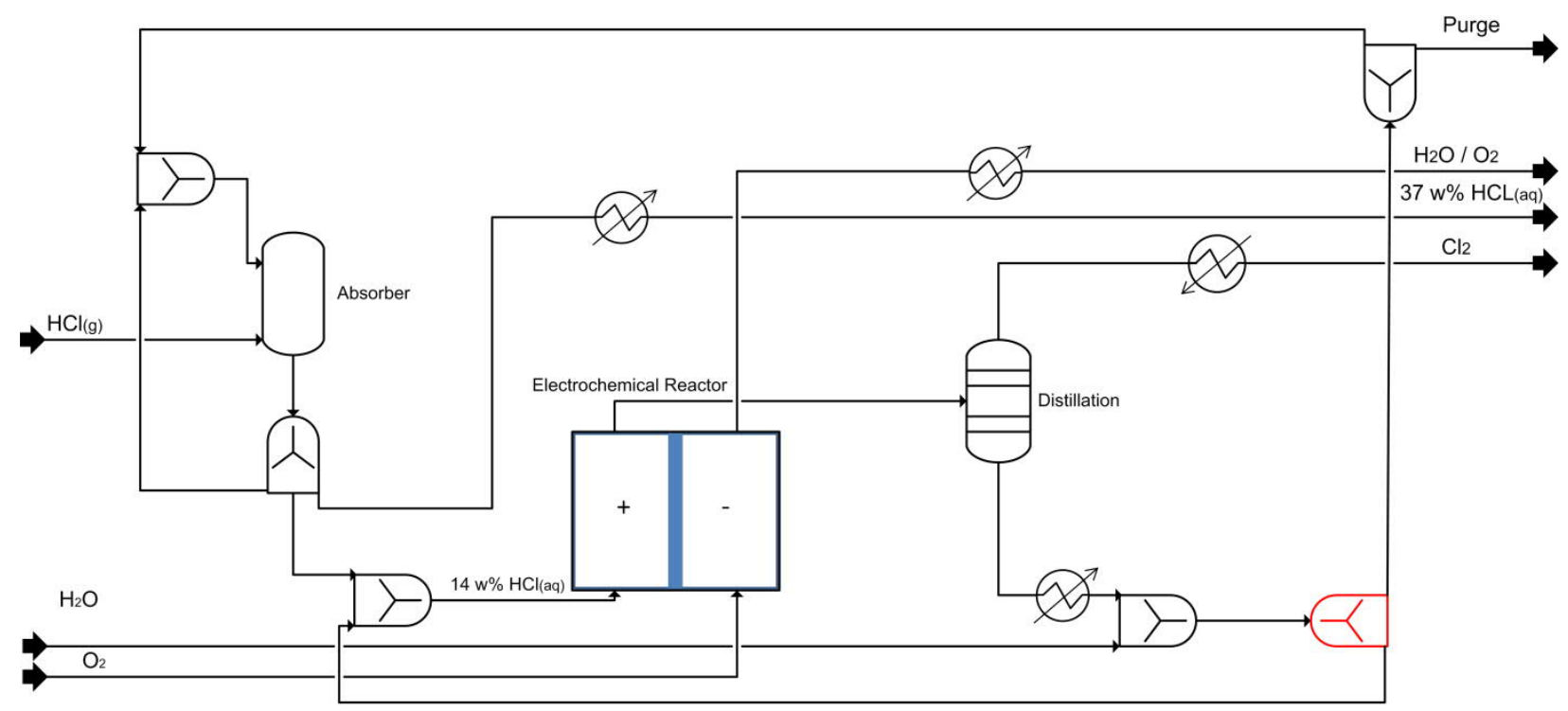

Fig. 2 Process flow scheme of the Bayer UHDENORA state-of-the-art process designed in Aspen Plus.

The ENRTL-RK method, a successor of the ELECNRTL model, was selected as a property model for the simulation of the state-of-the-art process, due to the presence of electrolyte species. The ENRTL-RK method employs an asymmetric reference state, meaning that infinite dilution of the aqueous phase is chosen as a reference state and it collapses into the NRTL-RK method when no electrolytes are existent [19]. Only the dissociation of hydrogen chloride in water and the auto-dissociation reaction of water were included as possible reactions in the chemistry settings. Chlorine however, was not defined as a reactive species which is due to the fact that the equilibrium constant for the dissociation reaction of chlorine and water forming hypochlorous acid and hydrochloric acid is only about $4 \times 10^{-4} \frac{l^{2}}{m o l^{2}}$ at $17.6^{\circ} \mathrm{C}$ [20]. Taking into account that the concentration of hydrochloric acid after the electrochemical reactor is approximately $11 \mathrm{wt} \%$, the equilibrium for the dissociation reaction of chlorine is even further shifted towards the 
molecular chlorine. Therefore, it is a good approximation to neglect the reaction of chlorine and water.

Due to the fact that both gases, hydrogen chloride and chlorine, are non-condensable under the conditions present in this process, they were defined as components obeying Henry's law. Since the critical temperature of hydrogen chloride is already at $325 \mathrm{~K}$ it is not condensable at conditions present in the distillation column [21]. At those temperatures, gas solubilities must be calculated by defining the gas as a Henry component or at high pressures above 10 bar, it is recommended to employ an equation of state model $[22,23]$. In the following sections the two newly developed processes including different methods for separating the chlorine from the remaining hydrogen chloride are discussed. The fact that in this new process ideally only gaseous hydrogen chloride and chlorine are present in the anode stream leaving the electrochemical reactor, allows for simply separating these gases based on their different boiling points. The second option is to exploit the difference in the solubility of both gases by absorbing chlorine in a non-polar organic solvent and to utilize a subsequent extraction step to remove the remaining hydrogen chloride residues from the solvent. In the following chapter the first one of these approaches is discussed in more detail.

\subsection{Gas phase reactor and $\mathrm{HCl} / \mathrm{Cl}_{2}$ separation via distillation (ELECTRA-DIST process)}

In the classical Deacon process and its advanced successors like the Shell or UTC process, a gas mixture of chlorine, residues of hydrogen chloride and oxygen remains after separating the water and most of the hydrogen chloride from the reactor outlet stream. This gas mixture can be 
separated by compressing and cooling and thereby liquefying the chlorine [24]. A similar procedure is discussed in the work of Foster et al. [25]. In a patent from Gestermann et al. [26] a subsequent distillation step is mentioned to separate the chlorine and remaining hydrogen chloride. As explained in the following section, the absorption of hydrogen chloride in water in the novel process variants is not feasible. Therefore, a distillation column is proposed as the only necessary separation step. Contrary to the patent of Gestermann et al. [26], the feed of the distillation does not only contain impurities of hydrogen chloride but is equivalent to the anode outlet stream of the chemical reactor and, depending on the single pass conversion, consists of significant amounts of hydrogen chloride. A significant advantage compared to the Deacon like processes is that the hydrogen chloride emerging from the top of the distillation column can be redirected to the reactor, since it is not absorbed in water. Therefore, the electrochemical gas phase process theoretically allows for very high overall conversions of up to $100 \%$. Furthermore, assuming that no oxygen is present in the $\mathrm{HCl} / \mathrm{Cl}_{2}$ mixture at the reactor outlet, the overall gas separation becomes more simple and energy-efficient.

Contrary to the liquid phase processes like the Bayer UHDENORA and the Uhde process, the DuPont gas phase process features a conversion of up to $85 \%$ [27]. This is due to the fact that in gas phase processes, no restrictions regarding conductivity and oxygen evolution in the anode chamber have to be regarded, since no water is present. For the gas phase reactor, Kuwertz et al. measured a cell potential of $0.977 \mathrm{~V}$ at a current density of $4000 \mathrm{kA} \mathrm{m}^{-2}$ and a conversion of $30 \%$ [12]. Martinez [4] has proven in his half-cell measurements of the hydrogen chloride oxidation that reducing the concentration of hydrogen chloride in the feed stream to $40 \%$ leads to an overpotential increase of less than $0.07 \mathrm{~V}$ at a technical relevant current density of $4 \mathrm{kA} \mathrm{m}^{-2}$. 
This indicates that a conversion of $60 \%$ and more in the gas phase reactor is possible with only a relatively small increase in the cell potential. The lower oxygen concentration in the cathode chamber linked to an increase of the $\mathrm{HCl}$ conversion also leads to an increased potential drop. However, as stated in the work of Ooms et al. [17] oxygen is usually fed into the reactor with an excess of $100 \%$. Therefore, taking into account the stoichiometry of the reaction, a conversion of $60 \%$ with regard to $\mathrm{HCl}$ would result in a decrease of the oxygen concentration of only $15 \%$. This shows that a potential drop on the cathode side due to an increase in conversion can be easily damped with a sufficient oxygen excess. Decreasing the hydrogen chloride concentration in the feed gas down to $20 \%$, lead to a further slight increase in the potential drop and to a decline in the current density, which reached a plateau at $3 \mathrm{kA} \mathrm{m}^{-2}$ [4]. However, it has to be considered that a feed concentration of $20 \%$ is not equivalent to a $\mathrm{HCl}$ conversion of $80 \%$ within the reactor, since in the latter case the $\mathrm{HCl}$ concentration is decreasing from $100 \%$ to $20 \%$, reaching its lowest value only at the end of the reactor. Therefore, for this work, the novel process variants were simulated with a single pass conversion of $60 \%$ and $80 \%$ but a fixed overall conversion of $80 \%$, as discussed in the introduction, in order to study the influence of the conversion on the exergy demand and to examine whether the novel process variants are also feasible with a lower single pass conversion of only $60 \%$. The cell potential, which was chosen for all simulations and the exergetic assessment, is $1 \mathrm{~V}$. This value is equivalent to an energy consumption of $730 \mathrm{kWh}$ per ton of chlorine and slightly higher than the experimental value from Kuwertz et al. [12] taking into account the above discussed small increase in the concentration overpotential due to a higher conversion. This increase is of course a function of the conversion, however due to the small contribution of $0.07 \mathrm{~V}$ at most, assuming a constant voltage of $1 \mathrm{~V}$ is a good approximation until more precise experimental data is available that 
describes the overpotential of the whole electrochemical cell for different conversions. In the case of $80 \%$ single pass conversion, all hydrogen chloride in the distillate stream of the column can be dissolved in water and discharged as concentrated hydrochloric acid. However, for a single pass conversion of $60 \%$ a hydrogen chloride recycle stream has to be established. Fig. 3 depicts the according process flow scheme.

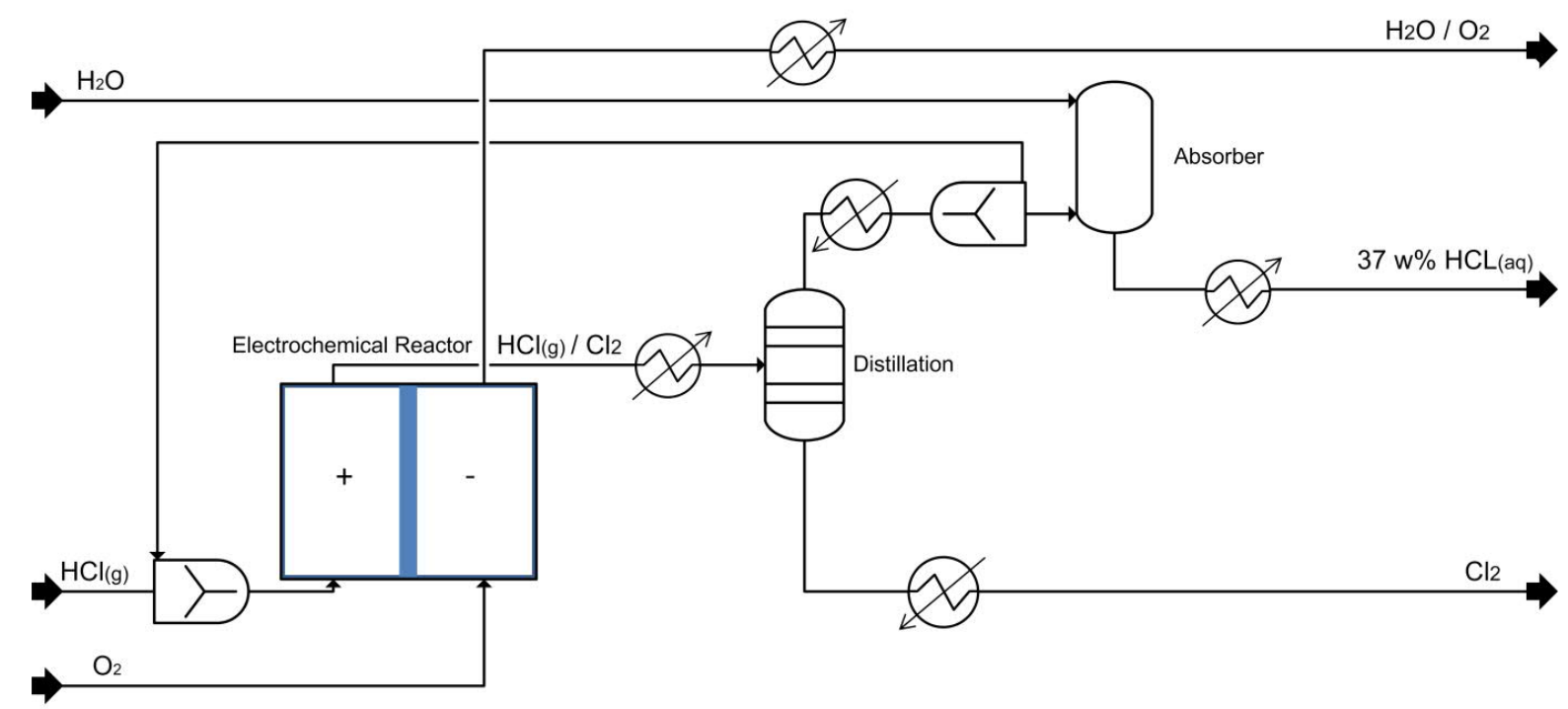

Fig. 3 Process flow scheme for the newly developed process based on a separation of the chorine and hydrogen chloride through distillation. From an exergetic point of view it is most feasible not to compress the feed gas of the distillation column. However, from a practical point of view column operation at increased pressure is beneficial due to higher boiling temperatures of both gases which makes it easier and cheaper to provide suitable cooling media. Therefore, simulations at pressure levels of 2, 5, 8 and 10 bar were carried out (compare exergetic analysis in section 3).

In this process, the predictive SRK method (PSRK) was chosen as the property model. It is based on the Soave-Redlich-Kwong equation of state and a mixing rule in which the excess Gibbs free energy estimated from the UNIFAC method is incorporated [28]. The advantage is a better accuracy compared to the SRK method if polar components like hydrogen chloride are present in the gas mixture. At higher pressures, this method is also more precise than the UNIFAC model 
$[28,29]$. Additionally, since PSRK is still an equation of state it can be applied to mixtures with supercritical components as they occur if the gases are compressed prior to distillation [28]. To ensure the validity of the PSRK method in this specific case, the column was also simulated with the NRTL-RK method and deviations of only $1 \%$ in the heat duty and $2 \mathrm{~K}$ in the reboiler and condenser temperatures between both variants have been observed. Therefore, PSRK can be considered as a suitable property method for simulating this process. The absorption of hydrogen chloride in water to form hydrochloric acid however, must still be modeled with ENRTL-RK due to the presence of ionic species. The reflux ratio, the distillate to feed ratio and the number of stages of the distillation column were chosen in a way that the required heat duty is minimized and the purity specifications are satisfied.

\subsection{Gasphase reactor and $\mathrm{HCl} / \mathrm{Cl}_{2}$ separation via absorption and extraction (ELECTRA-} ABS process)

As an alternative to the previously described ELECTRA-DIST process, the following variant utilizes differences in the solubilities of chlorine and hydrogen chloride in an organic solvent. Dissolving hydrogen chloride in water and thereby separating both gases, as it is common in the heterogeneously catalyzed high temperature processes, was not considered for two reasons. Firstly, this would leave the remaining chlorine gas stream to be too humid so that an additional drying step is inevitable. Secondly, a part of the hydrogen chloride dissolved in water in the form of hydrochloric acid would have to be separated and fed back to the reactor. Due to the fact that hydrogen chloride is chemically absorbed in water this would be a highly energy intensive and very inefficient proposition. 
In the heterogeneously catalyzed high temperature processes, tetrachloromethane was proposed for the absorption of organic solvent impurities and parts of the chlorine [25]. However, as shown in the following, it is not possible to separate the chlorine from the remaining hydrogen chloride and oxygen by absorption alone while still satisfying the purity constraints given in this work. Therefore, a subsequent purification, for example through distillation, is still necessary. Yet, the concept of physical absorption of either chlorine or hydrogen chloride can also be applied to the newly proposed process. However, it has to be considered that the use of halogenated solvents is not sustainable and also restricted by law. Absorbing hydrogen chloride in polar organic solvents like acetic acid or acetone has the major disadvantages of a low selectivity, meaning that the solubility of chlorine is not significantly lower than the one of $\mathrm{HCl}$, and in some cases (e.g. acetone, DMSO) the solvent is not stable in the presence of hydrogen chloride. However, there is a range of common organic solvents in which the solubility of chlorine is distinctly higher than the one of hydrogen chloride, for example chloroform, benzene and alkanes. Especially the alkanes (C6-C12) are not only significantly less hazardous and more environmentally friendly than halogenated solvents but also inexpensive and readily available.

Experimental values of the solubilities and the Henry constants of hydrogen chloride and chlorine in water and several organic solvents were obtained from the Aspen database and in the case of chlorine, the solubility data series [30]. While higher alkanes have a slightly lower Henry constant for chlorine, their boiling point is also significantly increased leading to a higher required heat duty in the subsequent desorption step. Octane showed an overall much lower exergy demand compared to higher homologues like decane, which is the reason why it was 
chosen as absorption solvent in the present work. Utilizing decane instead of octane as a solvent for example leads to an additional exergy demand of ca. $0.8 \mathrm{MW}$. In future investigations, heptane and hexane should also be examined, even though it has to be considered that the lower alkanes also dissolve slightly more water which can be problematic as explained later in this section.

However, despite of a distinct difference in the Henry constants of chlorine and hydrogen chloride, the selectivity of the absorption step is not high enough, so that either a significant amount of hydrogen chloride is also absorbed in the solvent or a huge proportion of chlorine remains in the gas stream leaving the top stage of the absorber. The following calculation illustrates this problem. As specified earlier, the purity of the chlorine product should be at least $99.5 \mathrm{wt} \%$ which is equivalent to a molar fraction of $99 \%$. From this condition follows:

$$
x_{C l_{2}} \geq \frac{0.99}{0,01} x_{H C L}
$$

With the equilibrium constant $K_{i}=\frac{y_{i}}{x_{i}}=\frac{H_{i}}{p}$ and under the assumption that the gas phase only contains negligible amounts of solvent follows:

$$
\begin{gathered}
\frac{y_{C l_{2}}}{K_{C l_{2}}} \geq 99 \frac{1-y_{C l_{2}}}{K_{H C L}} \\
y_{C l_{2}} \geq 99 \frac{K_{C l_{2}}}{K_{H C L}\left(1+99 \frac{K_{C l}}{K_{H C L}}\right)}=99 \frac{H_{C l_{2}}}{H_{H C L}\left(1+99 \frac{{ }_{C l}}{H_{H C L}}\right)} \geq 95.2 \%
\end{gathered}
$$


This means that the gas phase has to consist of at least $95.2 \%$ chlorine during the absorption process, not even taking into account that the solvent becomes more and more saturated with chlorine in the course of the absorption. If there is less than $95.2 \%$ chlorine in the gas phase, the amount of absorbed hydrogen chloride in the octane is too high, so that after the desorption step the chlorine product stream contains more than $0.5 \%$ hydrogen chloride. This high concentration of chlorine in the gas stream is not realistic and would also mean that nearly all of the chlorine is leaving the column on the top stage together with the not absorbed hydrogen chloride which again would have to be separated. The influence of the amount of octane on the mole fractions of absorbed chlorine and hydrogen chloride is depicted in Fig. 4.

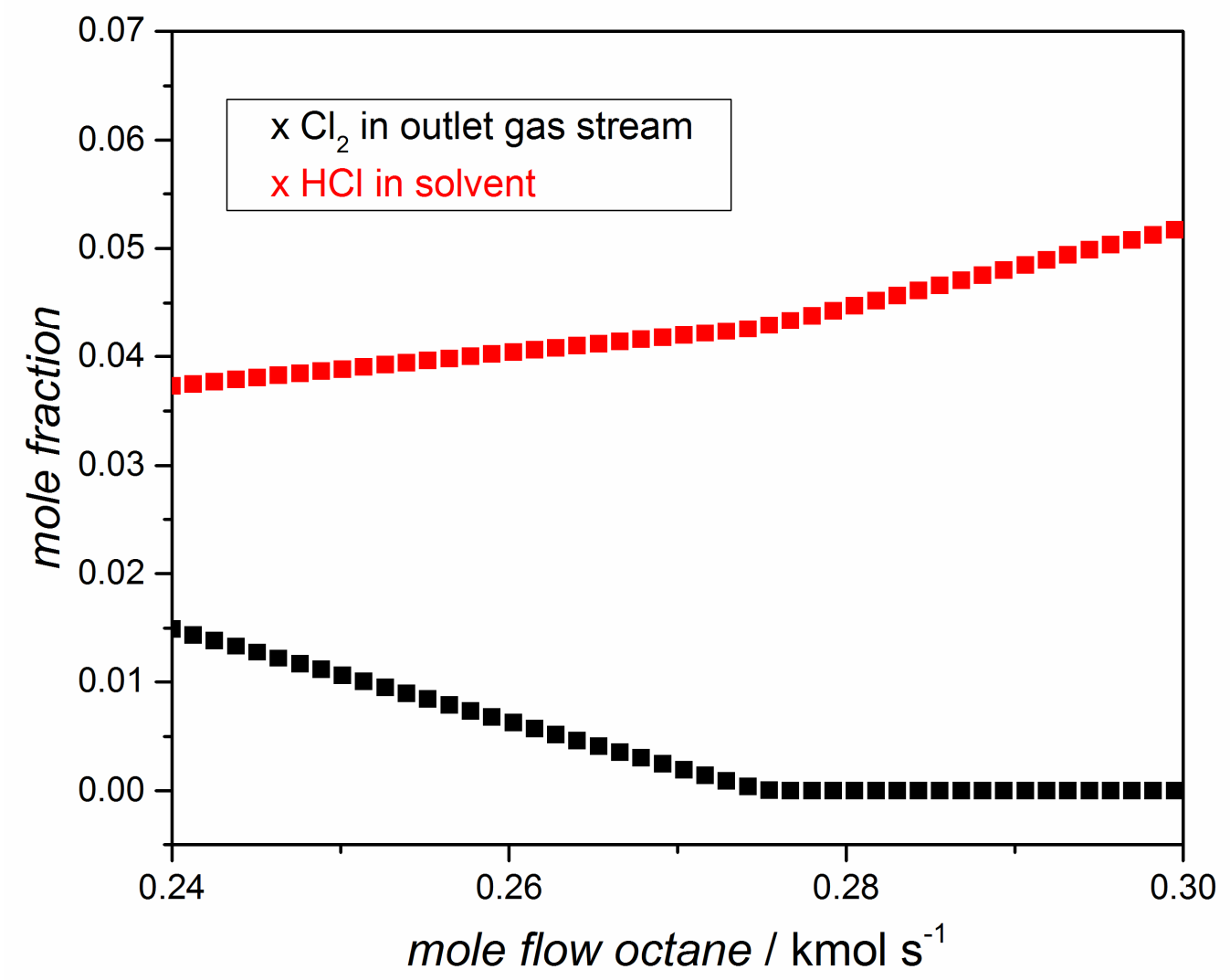

Fig. 4 Sensitivity analysis of the absorption unit with octane as solvent. The red data points represent the mole fraction of hydrogen chloride in the solvent after the absorption step and the black points depict the mole fraction of 
chlorine in the gas stream leaving the column as a function of the molar flow of octane. In order to absorb all the incoming chlorine at standard temperature and pressure, slightly more than $0.27 \mathrm{kmol} \mathrm{s}^{-1}$ octane would be necessary. However, the solvent stream leaving the absorber would then also contain $4 \%$ hydrogen chloride, which is about half of the hydrogen chloride entering the column.

Therefore, the application of physical absorption alone is not sufficient. The key is to employ the exact amount of octane necessary to absorb practically all of the chlorine. In this case, the gas stream leaving at the top of the absorber consists of almost pure hydrogen chloride with only traces of octane and chlorine. If the conversion in the reactor already is at $80 \%$, this hydrogen chloride stream can be absorbed in water forming concentrated hydrochloric acid which leaves the process as a product stream. However, if the single pass conversion in the reactor is lower, for example $60 \%$, a part of the gas leaving the column has to be recycled back to the reactor so that the overall conversion remains at $80 \%$.

Now that the hydrogen chloride gas stream is pure enough to be either dissolved in water or recycled, the chlorine absorbed in octane has to be separated from the significant amount of nonconverted hydrogen chloride that is absorbed in octane as well. For that reason, a subsequent extraction unit using pure water as solvent is proposed. In this unit, all of the hydrogen chloride absorbed in octane dissolves in the water phase due to the highly exergonic dissociation reaction. By subsequently absorbing the pure hydrogen chloride from the top of the absorption column in this aqueous solution, a $20 \%$-fraction of the overall hydrogen chloride feed leaves the process in the form of concentrated hydrochloric acid as desired. The remaining octane phase now only contains chlorine and traces of water. The equilibrium mole fraction of water in octane at room temperature is $5 \times 10^{-4}$ and the fraction of octane in water is $9.96 \times 10^{-8}$. This number has been calculated as a mean value from experimental data extracted from Maczynski et al. [31]. 
The low miscibility of water and octane only leads to negligibly small impurities of water in the octane stream and of octane in the hydrochloric acid stream. Subsequently, chlorine can be desorbed in a distillation column and discharged as a product stream while the octane stream leaving at the bottom of the distillation column is recycled.

The necessary amount of octane for the absorption step and therefore the heat duty in the distillation column can be reduced, if the gas stream is compressed prior to absorption. According to Henry's law, the mole fraction of the gas in the liquid phase increases linearly with the partial pressure of this substance in the gas phase. However, the energy savings in the distillation unit have to be compared to the additional need of electrical energy in the compressor. Simulations with an outlet pressure of 1.013, 2.026 and 8.104 bar in the compressor unit were carried out and the most exergy efficient configuration was obtained at a pressure of 8.104 bar. The compression and expansion was set to be isentropic using the ASME method. Therefore, this value was used for the following simulation; in future investigations the optimal pressure should be determined systematically. In these optimizations it must be taken into account that chlorine has a vapor pressure of 9 atm at $30^{\circ} \mathrm{C}$ [32]. Therefore, the temperatures in the compression step and the feed of the absorption column must be adjusted, if a second liquid phase is to be avoided. A higher temperature in the absorption column would however adversely affect the selectivity and hence the efficiency of the absorption, since the Henry constant of chlorine in octane increases more strongly with temperature than the Henry constant of $\mathrm{HCl}$ in octane. Additionally, higher pressures of the hazardous $\mathrm{HCl} / \mathrm{Cl}_{2}$ mixture come hand in hand with and increased safety risk and lead to higher investment costs in the subsequent equipment due to the need of thicker walls. Fig. 5 shows the flowsheet of this process variant. 


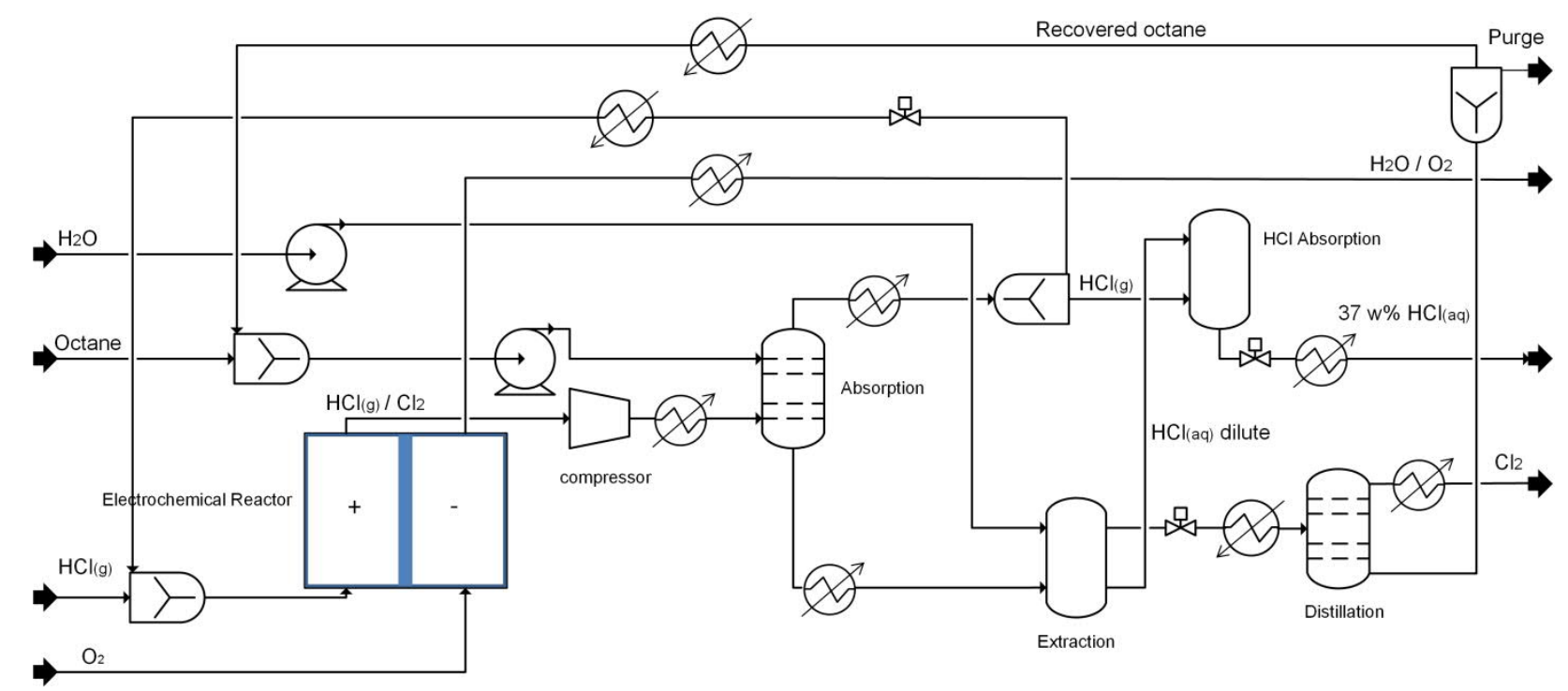

Fig. 5 Process flow scheme for the ELECTRA-ABS process in which the gas separation is realized by an absorption unit followed by an extraction step and a subsequent desorption of the chlorine. Again, this process variant was simulated twice with a single pass of $60 \%$ and $80 \%$ while the overall conversion was held constant at $80 \%$.

As before, the hydrogen chloride absorption has been simulated with the ENRTL-RK method. The absorption step can be best described with the NRTL-RK method, since no ionic species are present. At first, the distillation column was also simulated based on the NRTL-RK model, however, convergence problems occurred for no obvious reasons when the octane recycle stream was closed although the feed composition of the column remained constant. Due to this, the distillation unit has been modelled with the PSRK method, which has already been introduced in this section. This led to a stable simulation. The PSRK model was preferred over the SRK method due to the presence of small amounts of water in the column feed. Since the pressure in the absorption column is at 8 bar, the use of an equation of state model like PSRK is justified. 


\section{Calculations}

\subsection{Phase equilibrium in the extraction step of the ELECTRA-ABS process}

The extraction step could not be simulated in a physically and chemically consistent way with the extraction apparatus available in Aspen Plus, due to the complex nature of the mixture. Therefore, the extraction has been described analytically and then implemented into a separator block in Aspen with the help of design specifications. Hereby, the distribution of chlorine between the octane and the aqueous phase is most important. This is due to the fact that the chlorine transferred into the aqueous phase would contaminate the hydrochloric acid stream by forming hypochloric acid and parts of it would also degas as soon as the pressure is reduced after the extraction step which poses an environmental issue. Furthermore, the transferred amount of chlorine should be as small as possible for economic reasons to maximize the overall chlorine yield. It has to be considered that the hydrogen chloride, which completely dissolves in the aqueous phase forming hydrochloric acid in the extraction step, influences the equilibrium distribution of chlorine between the two phases. Alkan et al. [33] have investigated the solubility of chlorine in hydrochloric acid for $\mathrm{HCl}$ concentrations of up to $7 \mathrm{~mol} \mathrm{~L}^{-1}$. Combined with the mutual solubility data of water and octane given by Maczynski et al. [31], the liquid-liquidequilibrium concentrations of each substance $i$ in the two phases can be approximated. At phase equilibrium the chemical potential of a substance is the same in each phase $l$. Due to the equivalent pressure and temperature in each phase the same condition holds for the fugacity $f_{i, l}$ of the component. Neglecting the Poyinting correction factor, the following equation can be formulated 


$$
f_{i, l}=\gamma_{i, l} x_{i, l} p_{i, s a t} \varphi_{i, s a t}
$$

In equation $4, \gamma_{i, l}$ represents the activity coefficient of substance $i$ in phase $l, x_{i, l}$ its molar fraction, $p_{i, s a t}$ the saturation pressure of the pure component and $\varphi_{i, s a t}$ the related fugacity coefficient. This fugacity coefficient is not a function of the composition of the mixture, since it is a property of the respective pure component. Additionally, at low concentrations of the dissolved gas, Henry's law is a good approximation for the saturation pressure. This leads to the following relation:

$$
f_{i, l} \sim \gamma_{i, l} x_{i, l} H_{i, l}
$$

For small concentrations of the absorbed gas, the activity coefficient is approximately one. From that follows that the mole fraction of a component in each phase is inversely proportional to its Henry constant under equilibrium conditions.

$$
\frac{x_{C l_{2}, \text { water }}}{x_{C l_{2}, \text { octane }}}=\frac{\frac{\dot{n}_{C l_{2}, \text { water }}}{\dot{n}_{C l_{2}, \text { water }}{ }^{+\dot{n}_{\text {water }}}}}{\frac{\dot{n}_{C l_{2}, \text { octane }}}{\dot{n}_{C l_{2}, \text { octane }}+\dot{n}_{\text {octane }}}}=\frac{H_{C l_{2}, \text { octance }}}{H_{C l_{2}, \text { water }}} \equiv K
$$

In equation $6, \dot{n}_{C l_{2}, \text { water }}$ and $\dot{n}_{C l_{2}, \text { octane }}$ are the molar equilibrium fluxes of chlorine in the water and octane stream leaving the extraction unit. The molar flux of pure water fed into the extraction unit is defined as $\dot{n}_{\text {water }}$ and $\dot{n}_{\text {octane }}$ represents the molar flux of octane coming into the extractor. The small amount of hydrogen chloride present in the octane stream is neglected in this balance. However, the Henry constant of chlorine in water $H_{C l_{2}, \text { water }}$ is influenced by this 
amount of hydrogen chloride which transfers into the water phase during the extraction step and affects the solubility of chlorine in water. This effect is considered by extrapolating the solubility data of Alkan et al. [33] as shown below and in Fig. 7. Based on the balance condition that the molar flux of chlorine $\dot{n}_{\mathrm{Cl}_{2}}$ entering the extraction and the molar flux of chlorine transferred into the water and octane phases during the extraction process is equivalent, the distribution of chlorine between the two outlet streams of the extraction unit can be calculated. The final equation and a simplified form of it can be found in the supplemental information (SI.1 and SI.2). Fig. 6 visualizes the different molar fluxes entering and leaving the extraction unit.

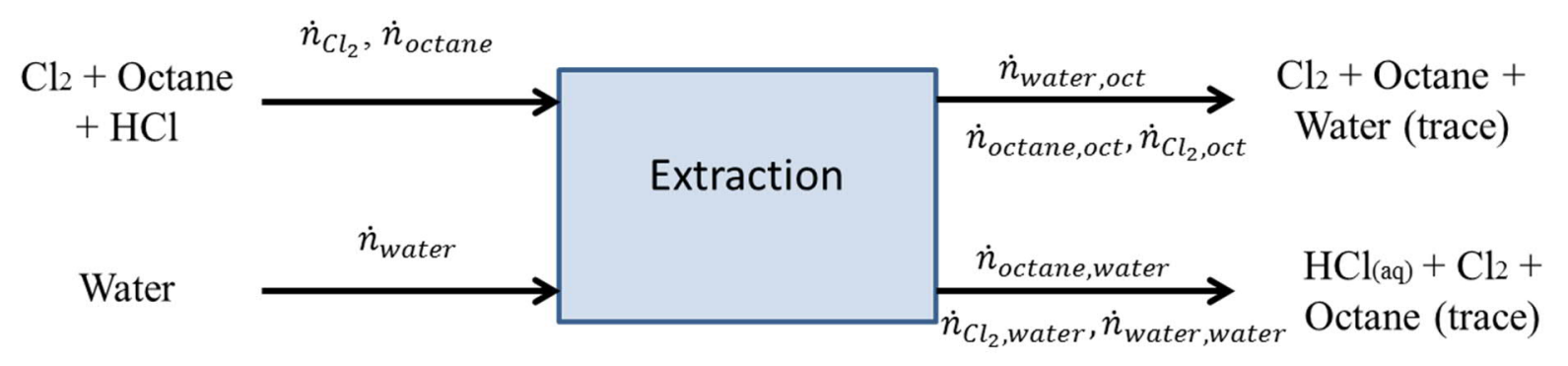

Fig. 6 Visualization of the extraction process including the relevant molar fluxes for the approximation of the equilibrium composition of the two outlet streams

Alkan et al. [33] have investigated the dependence of the chlorine solubility on the concentration of hydrochloric acid. However, they have only considered hydrochloric acid concentrations of up to $7 \mathrm{~mol} \mathrm{~L}^{-1}$. In all simulations of the present work, apart from the variant with a single pass conversion of $60 \%$ and a total conversion of $80 \%$, the hydrochloric acid concentration is below $7 \mathrm{~mol} \mathrm{~L}^{-1}$. The experimental results of Alkan et al. [33] show a linear trend of the solubility of chlorine in hydrochloric acid for concentrations greater than $1 \mathrm{~mol} \mathrm{~L} \mathrm{~L}^{-1}$. Therefore, a linear fit based on the data points of Alkan et al. [33] has been used for the extrapolation of the chlorine 
solubility towards higher hydrochloric acid concentrations as shown in Fig. 7 for the temperatures of $293 \mathrm{~K}$ and $303 \mathrm{~K}$.

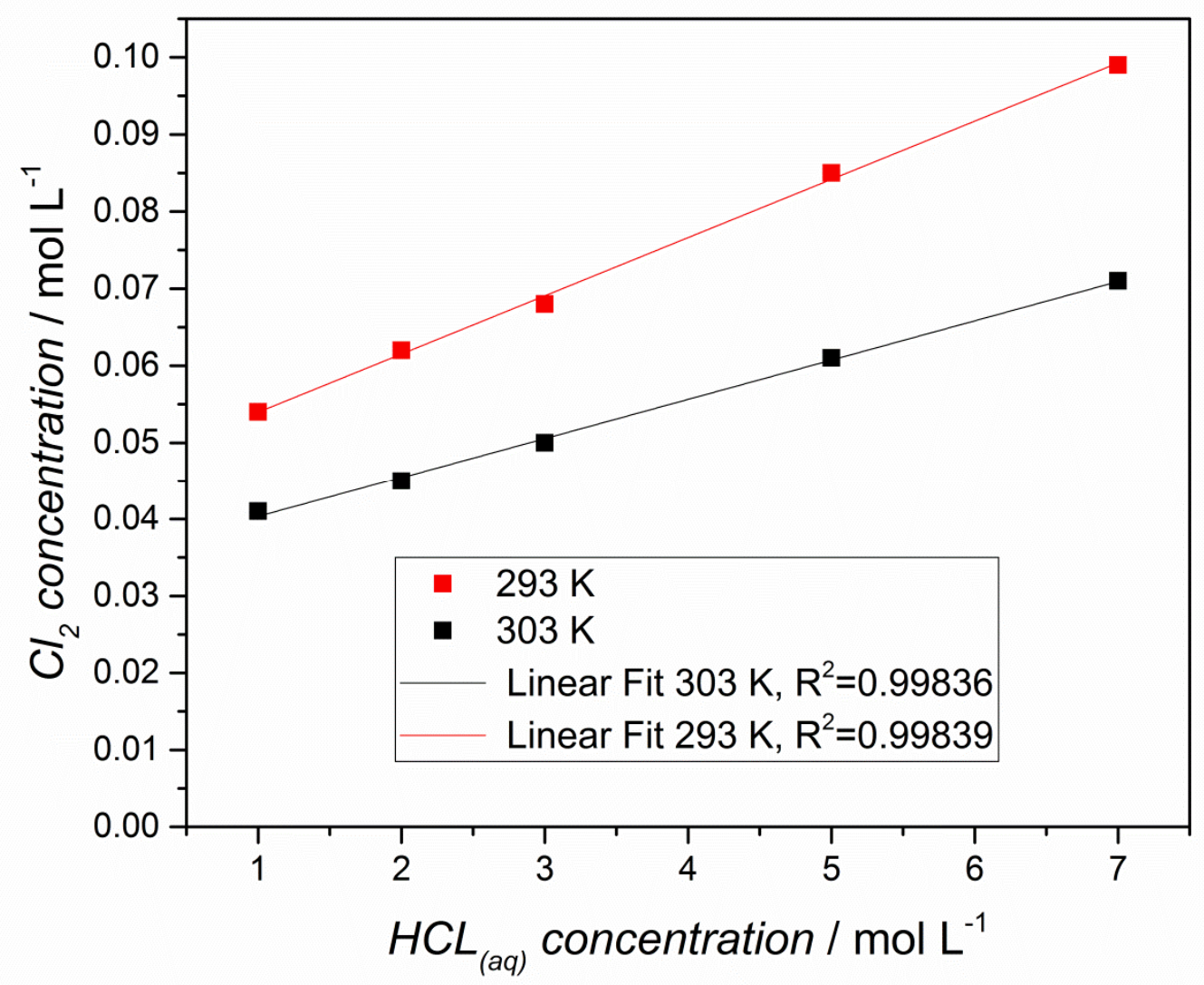

Fig. 7 Linear fit to the data points from Alkan et al. [30] in the concentration range from 1-7 mol $\mathrm{L}^{-1}$ hydrochloric acid. The diagram shows a very good agreement of the linear fit with the experimental data. Since the temperature interval from 293 to $303 \mathrm{~K}$ is reasonably small, the solubility at $298.15 \mathrm{~K}$ is approximated by linear interpolation between these two temperatures.

Based on the above calculations, the equilibrium concentrations of chlorine in both phases can be determined. Furthermore, the equilibrium mole fractions of water and octane in the water-rich and the octane-rich phase are known from Maczynski et al. [31]. It is assumed that the presence of chlorine and hydrogen chloride has no significant impact on the miscibility of octane and water, which seems to be a justifiable approximation since the amount of octane and water is significantly greater than the amount of dissolved gases. The calculation of the amount of water 
and octane in each phase after the extraction step can be found in the supplementary information (SI. 3-6).

Thereby, it is possible to estimate the performance of the extraction. Although the assumptions made in the above calculations are physically reasonable, small deviations of the results from the real LLE are to be expected. Therefore, an additional simulation has been carried out where the amount of all substances changing the phase in the extraction unit has been increased by $50 \%$. This is supposed to represent a worst case scenario in which more chlorine is lost via the aqueous phase and more octane and water impurities will be found in the corresponding aqueous and organic phase. The exergetic analysis was also executed for this worst case scenario in order to determine the sensitivity of the developed process with respect to the uncertainties in the determined equilibrium concentrations of the extraction step.

To sum up, two novel processes have been proposed and simulated. Both of them fulfill the requirements regarding the purity of the product. In the following section, the methods applied for calculating the exergy demand of these processes are discussed.

\subsection{Exergetic assessment}

As stated in the introduction, the difference in the exergy input and output of all processes can be calculated by only taking into account all work and heat streams entering and leaving the overall system envelope, since the inlet and outlet material streams of all processes are approximately identical. While the electrical energy needed for the compressors or the electrochemical reactor 
consists of pure exergy, the heat streams entering and leaving the process contain an anergetic part as well. The exergy flow $\dot{B}$ of a heat stream at constant temperature can be calculated based on equation 13 [34,35]:

$$
\dot{B}=\dot{Q}\left(1-\frac{T_{a}}{T}\right)
$$

Hereby, $\dot{Q}$ is the heat stream, $T$ is the temperature at which the heat is transferred and $T_{a}$ is the reference temperature which is chosen to be $298.15 \mathrm{~K}$ in this work. At operating temperatures below the ambient temperature the direction of the flow of exergy is opposite the direction of the heat flow. If the temperature is not constant, like in heat exchangers, the exergy is calculated from equation 14 assuming that the operating pressure is constant:

$$
\dot{B}=\int\left(1-\frac{T_{a}}{T}\right) d \dot{Q}=c_{p} \int_{T_{a}}^{T}\left(1-\frac{T_{a}}{T}\right) d T
$$

In equation $14, c_{p}$ stands for the heat capacity at constant pressure. As in most electrochemical processes, the electricity needed to operate the reactor contributes significantly to the overall exergy demand of the process. In addition to the electrical power demand of the reactor, the reaction heat has to be considered. Normally, the simulator Aspen Plus determines the reaction heat and therefore the heat duty of a reactor. However, since the stoichiometric reactor defined in Aspen does not take the separation of the anode and cathode streams into account, it assumes complete mixing of all reactants and products even though they are not in contact with each other in the electrochemical cell. Therefore, the heat duty of the reactor is split up between the reactor itself and a subsequent fictive, ideal separator unit in Aspen Plus. For this reason, the theoretical 
reaction heat $\dot{Q}_{\text {reactor }}$ has been calculated according to equation 15 . Hereby a reactor temperature of $40{ }^{\circ} \mathrm{C}$ has been assumed which is based on the experimental measurements of the gas phase reaction from Kuwertz [12] and Martinez [4].

$$
\dot{Q}_{\text {reactor }}=\Delta_{R} \dot{H}^{\circ} X+\overline{c_{P}} \dot{m} \Delta T+P_{e l}
$$

In this equation, $\overline{C_{P}}$ stands for the heat capacity of the product mixture calculated as a mass weighted mean value of the heat capacities of all involved pure substances. $\Delta_{R} \dot{H}^{\circ}$ is the molar reaction enthalpy under standard conditions multiplied with the molar flow rate of hydrogen chloride, $\dot{m}$ the mass flow through the reactor, $X$ the conversion and $P_{e l}$ the electrical power input. The heat capacities and the standard enthalpies of formation were obtained from NIST [21]. In the calculations, water was assumed to be in the liquid phase. The vapor pressure of water at $40^{\circ} \mathrm{C}$ is $7400 \mathrm{~Pa}$. Based on the partial pressure of oxygen and its molar flowrate in the cathode reactor outlet stream, it can be calculated that only $2.7 \%$ of the water exiting the reactor would be in the vapor phase. The state of matter of water (gaseous or liquid) impacts the overall heat duty due to the vaporization enthalpy and the changes in the heat capacity. However, the overall heat dissipation of the reactor and therefore its exergetic portion is significantly higher than both of these effects. Together with the fact that the mole fraction of water in the gas phase is very small, it is a good approximation to calculate the heat dissipated in the reactor based on the assumption of purely liquid water. Moreover, oxygen was assumed to be only present in the gas phase. This can be considered to be a good assumption as well due to the following reason: The mole fraction of oxygen in water at $40^{\circ} \mathrm{C}$ is only 0.0000187 [36] and its absorption enthalpy in water is $9.05 \mathrm{~kJ} \mathrm{~mol}^{-1}$ [36] while the overall heat dissipation of the reactor amounts to more 
than $140 \mathrm{~kJ}$ per mole of converted $\mathrm{HCl}$ as calculated by equation 15 . Also the molar amount of converted $\mathrm{HCl}$ is $0.288 \mathrm{kmol} \mathrm{s}^{-1}$ for a conversion of $80 \%$ while the remaining molar flow rate of oxygen in the cathode outlet is only $0.018 \mathrm{kmol} \mathrm{s}^{-1}$ and therefore significantly smaller. Hence, not only the relative but also the absolute amount of dissolved oxygen is negligibly small.

Furthermore, it has to be taken into account that the heat duty is dependent on the reactor conversion. Since the overall conversion of all processes is the same, the product $\Delta_{R} \dot{H}^{0} X$ is constant in all cases; only the term $\overline{C_{P}} \dot{m} \Delta T$ differs due to the disparities in the composition and mass flow. The hereby calculated results are in good agreement with the sum of the heat duty of the reactor and the subsequent separation unit obtained from Aspen, obviously deducting the electrical power which is not included in the simulation. The deviation for the gas phase reactor for example is only $0.02 \%$ which supports the above explanation for the distribution of the total heat duty between the reactor and separation unit and confirms the correctness of the exergetic calculations.

As explained above, the chemical and physical exergies of the process streams are not required for comparing the exergy demand of the considered process configurations. However, in this work, the exergetic efficiency and the specific exergy demand per $\mathrm{kg}$ of produced chlorine have also been calculated, which requires the chemical exergy of the input and output streams. Additionally, a Sankey diagram for the ELECTRA-DIST process has been generated to visualize the exergetic analysis. Therefore, the chemical and physical exergy streams $\dot{B}_{c h e m}$ and $\dot{B}_{\text {phys }}$ of every material stream in this process variant have been determined as well, using the following equations $[34,35]$. 


$$
\dot{B}_{p h y s}=\dot{H}(T, p)-\dot{H}\left(T_{a}, p_{a}\right)-T_{a}\left(\dot{S}(T, p)-\dot{S}\left(T_{a}, p_{a}\right)\right)
$$

The chemical exergy of substances that are present in the environment, e.g. atmosphere, is calculated based on their concentrations within the stream in comparison to their concentrations in the environment. The chemical exergy $B_{c h e m, j}$ of substances that are not a part of the environment is determined by generating them from reactions of substances $i$ that are existing in the environment and the according standard Gibbs free energy of reaction $\Delta_{R} G^{\circ}$ [35]:

$$
B_{\text {chem }, j}=\sum_{i} v_{i} B_{i, c h e m}(\text { environment })+\Delta_{R} G^{\circ}
$$

If a stream contains more than one substance, the mixing entropy has to be considered, leading to equation 18, with $x_{i}$ being the molar fraction of substance $i$ and $\gamma_{i}$ being its activity coefficient [34,35]. However, if the entropy term in equation 16 already includes the mixing entropy, it must not again be considered within the calculation of the chemical exergy:

$$
B_{\text {chem,mixture }}=\sum x_{i} B_{i, \text { chem }}+R T_{a} \sum x_{i} \ln \left(\gamma_{i} x_{i}\right)
$$

The chemical exergy value for octane is available in Morris et al. [20] and the ones for chlorine, oxygen, hydrogen chloride and water stem from Szargut [37]. The chemical exergy of hydrochloric acid is a complex function of its concentration, which is indicated by the strong dependence of the activity coefficient of the chloride and hydronium ion on the acid concentration. Hydrochloric acid with a concentration of $37 \mathrm{wt} \%$ as present in the discussed 
processes consists of 3.44 mole water per mole of hydrogen chloride. Therefore, the chemical exergy can be determined according to equation 19 :

$$
B_{\text {chem }, 37 \% H C l}=\dot{n}_{H C l}\left(b_{\text {chem }, H C l}+3.44 b_{\text {chem }, \text { water }}+\Delta_{R} G^{\circ}\right)
$$

Here, $b$ stands for the molar exergy of a substance and $\dot{n}_{H C l}$ is the molar feed of hydrogen chloride to the process. The value of $\Delta_{R} G^{\circ}$ has been determined from an absorption simulation of 1 mole hydrogen chloride in 3.44 mole water at standard conditions with Aspen Plus. The simulation results deliver the reaction enthalpy and entropy from which a value of $-19.45 \mathrm{~kJ} \mathrm{~mol}^{-1}$ was calculated for $\Delta_{R} G^{\circ}$. To ensure the validity of the results, the activity coefficients computed in Aspen Plus have been compared with experimental values from Kaiyuan and Hongyi [38] and were found to be in good agreement even at a concentration of $37 \mathrm{wt} \%$.

\section{Results and discussion}

\subsection{Exergy demand of the different process variants}

In this section, the results of the exergy assessment of the different process variants are analyzed. The overall exergy demand in the form of heat streams and electrical power input for the stateof-the-art process and for the two proposed novel processes, evaluated at single pass conversion of $60 \%$ and $80 \%$ is summarized in Table 2 . In this section, the chemical exergy of the feed and output streams is not included in the analysis, since it is identical in all process configurations. 
The exergy consumption of the state-of-the-art process is $42.3 \mathrm{MW}$ while the most efficient variant, the ELECTRA-DIST process at a single pass conversion of $80 \%$, has a significantly lower demand of $26.26 \mathrm{MW}$. This is equivalent to overall energy savings of $38 \%$. Decreasing the single pass conversion to $60 \%$ leads to a slightly higher exergy demand of $26.45 \mathrm{MW}$. This shows that also a lower single pass conversion operation of the gas-phase process is still much more efficient than the state-of-the-art process, which was one of the key questions motivating this work. The results even indicate that if necessary, the single pass conversion could be further decreased without significantly increasing the exergy demand.

Comparing the results of the process variants ELECTRA-DIST and ELECTRA-ABS shows that the former one only has a $2.7 \%$ lower exergy consumption. However, the data in Table 2 indicate that the exergy consumption of process variant ELECTRA-ABS is more strongly affected by decreasing the single pass conversion than the ELECTRA-DIST process. Here, the exergy demand at $60 \%$ single pass conversion is $1.3 \mathrm{MW}$ higher than for the $80 \%$ single pass conversion case. This is due to the fact that at lower conversions more octane is needed for chlorine absorption since more of the competing component hydrogen chloride is present in the gas mixture leaving the electrochemical reactor. The more octane is employed, the higher is the heat duty in the distillation column used for chlorine desorption. Furthermore, the power demand in the compression unit is significantly elevated due to the augmented amount of non-converted hydrogen chloride. Therefore, the ELECTRA-ABS process variant is less attractive compared to the ELECTRA-DIST variant, if for some reasons only a small single pass conversion could be achieved in a real production plant. This correlation is further underlined in the discussion of the exergy dependence on the overall conversion later in this section. However, it has to be 
emphasized that the even the $60 \%$ single pass conversion case of the ELECTRA-ABS is still $33 \%$ more exergetically efficient than the state-of-the-art process.

The simulation of the worst case scenario as explained in the methodological section in which the amount of all the species that are transferred between the aqueous and the organic phase within the extraction unit have been increased by $50 \%$ showed a deviation in the overall exergy of only $0.1 \%$ while the product specifications could be still achieved. This demonstrates that the process is not sensitive even to severe changes or uncertainties in the liquid-liquid-equilibrium composition of the extraction unit.

There are two major reasons for the drastical exergy savings of the two novel process variants in comparison to the Bayer UHDENORA liquid phase process. Firstly, the gas phase reactor itself is significantly more efficient compared to the liquid phase reactor as already discussed in the introduction. Secondly, the absence of water in the anode outlet stream of the gas phase reactor allows for a more efficient separation either by distillation or the combination of an absorption, extraction and desorption step. In chapter 4.2, the worst case scenario of water in the anode outlet stream of the reactor due to crossover trough the membrane and its effect on the exergetic efficiency of the two process variants is further elaborated.

In the liquid phase reactor of the Bayer UHDENORA process however, the chlorine is separated from the anode stream by distillation. Due to the high heat capacity of water, this distillation step is very energy demanding. Additionally, since the single pass conversion in the liquid phase variant is limited to about $23 \%$, due to the reasons discussed before, huge recycle streams with a 
mass flow which is 25 times as high as the mass flow of the hydrogen chloride fed into the process are necessary to reach the overall conversion of $80 \%$. These enormous amounts of recycled hydrochloric acid further increase the heat duty of the distillation step significantly and contribute to the enormous difference in the exergetical efficiency between the Bayer UHDENORA process and the two novel proposed gas phase processes.

\section{Process variant}

\section{Exergy consumption / MW}

State-of-the-art

Process ELECTRA-DIST at $80 \%$ single pass conversion

Process ELECTRA-DIST at $60 \%$ single pass conversion

Process ELECTRA-ABS at $80 \%$ single pass conversion

Process ELECTRA-ABS at $60 \%$ single pass conversion
42.3

26.45

27.04

28.39

Table 2 Total exergy consumption of the analyzed five process configurations.

It can be summarized that the proposed ELECTRA-DIST and ELECTRA-ABS processes lead to significant exergy savings of up to $38 \%$ and $36 \%$, respectively, in comparison to the state-ofthe-art process. In both configurations, decreasing the single pass conversion just slightly impairs the exergetic efficiency. Furthermore, in the two novel process variants, only the not converted hydrogen chloride is dissolved in water at the very end of the process. In the state-of-the-art process however, all of the hydrogen chloride is already dissolved in water at the beginning, which makes the employed machines and apparatus much more prone to corrosion and increases the investment costs due to the need of more corrosion resistant material. Additionally, the recycle streams are markedly smaller in the novel processes leading to reduced apparatus sizes. 
Therefore, the new processes proposed in this work have tremendous economic and environmental advantages over the current state-of-the-art technology and allows for a more sustainable recycling of hydrogen chloride.

\subsection{Contribution of different process units to the overall exergy demand}

In the following, the presented exergy assessment is broken down into contributions from the reactor, pressure changers, heat exchangers and the distillation columns. Those contributions are given in Fig. 11-13 for three of the five process configurations listed in Table 2. The configurations with a single pass conversion of $60 \%$ were similar to the depicted ones with $80 \%$ and are therefore not shown. Hereby, bars with a positive sign stand for the exergy demand of a unit-group and a negative sign means that the specific operation leads to an exergy stream leaving the system.

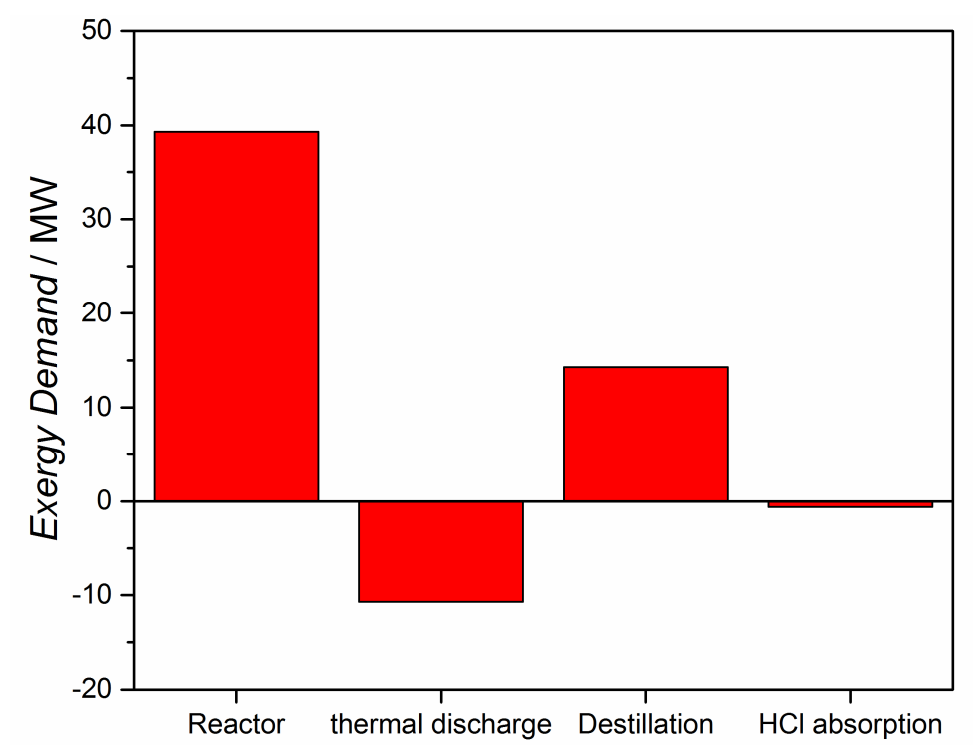

Fig. 11 Exergy demand of the reactor, distillation column, absorption column and the sum of all heat exchangers in the state-ofthe-art Bayer UHDENORA process. Negative values represent exergy streams leaving the system. 


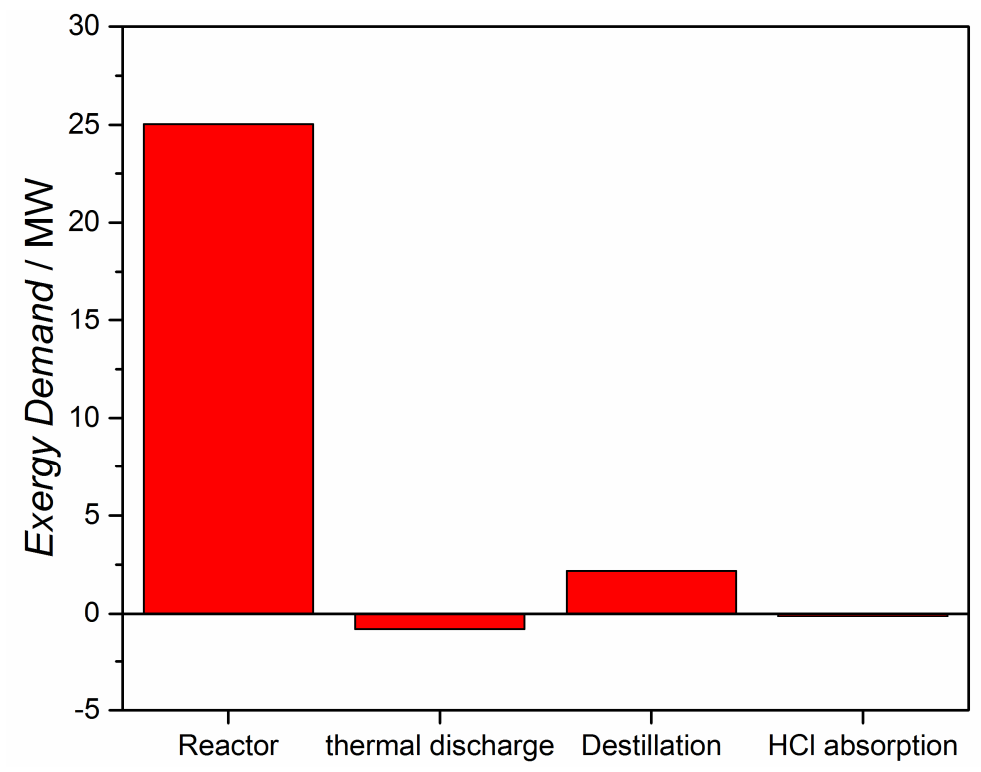

Fig. 12 Exergy demand of the reactor, distillation column, absorption column and the sum of all heat exchangers in the newly developed ELECTRA-DIST process with a single pass conversion of $80 \%$. Negative values represent exergy streams leaving the system.

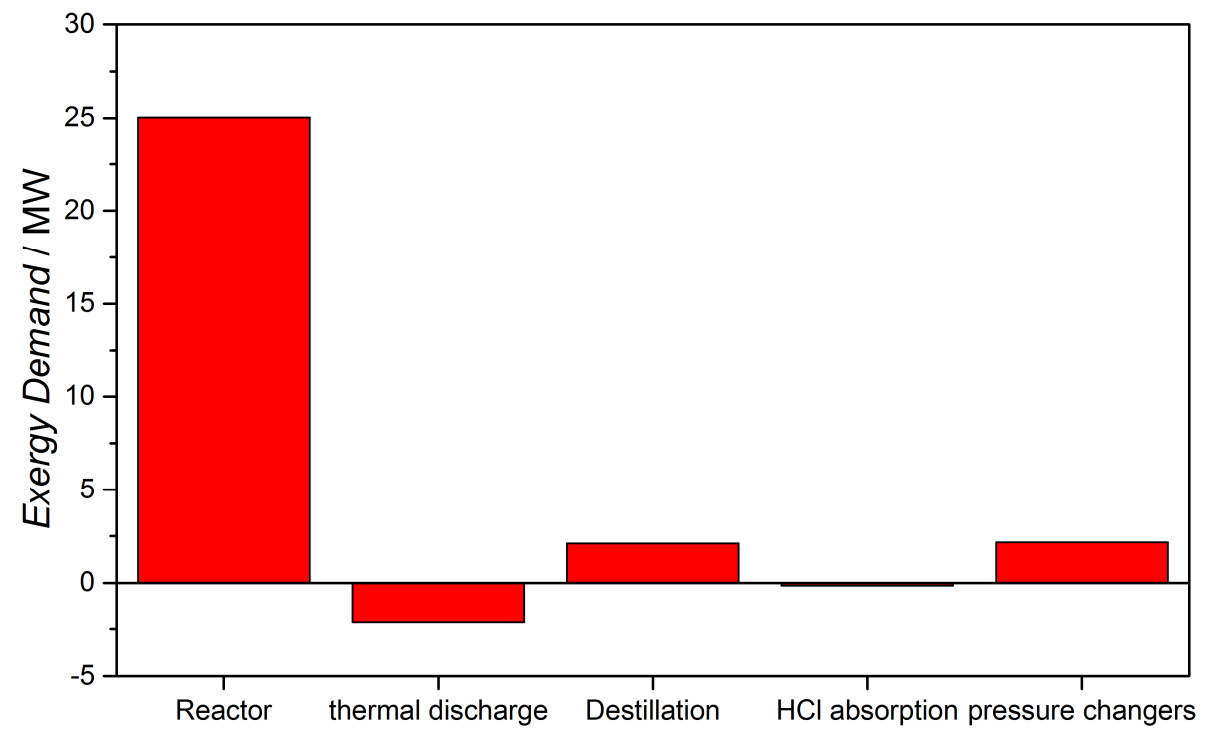

Fig. 13 Exergy demand of the reactor, distillation column, absorption column, pressure changers and the sum of all heat exchangers in the newly developed ELECTRA-ABS process with a single pass conversion of $80 \%$. Negative values represent exergy streams leaving the system. 
In all process variants, the electrochemical reactor conduces most to the overall exergy demand. This is especially striking in the novel ELECTRA-DIST and ELECTRA-ABS processes. While in the state-of-the-art technology, the exergy demand of the distillation column still makes up to $34 \%$ of the overall value, the contribution of the distillation to the total exergy consumption in the two novel processes is only between 7.8 and $10.2 \%$. Firstly, this shows again that not only the novel gas phase reactor concept itself is notably more efficient than the state-of-the-art liquid phase reactor but also the two proposed separation sequences. Secondly, one can conclude that the investigation and simulation of different separation methods is very important in order to evaluate the feasibility of the overall process, since an industrial application of the process is only possible under the condition of a viable separation of reactants and products. However, for the overall exergy demand of the process, the optimization of the reactor is much more significant. Furthermore, the choice of the best separation strategy is mainly dictated by practical, side specific decision factors, since the exergy demands of the ELECTRA-DIST and the ELECTRA-ABS process are nearly identical. These findings are underscored by the Sankey diagram of the ELECTRA-DIST process, assuming a single pass conversion of $80 \%$ (see Fig. 8). 


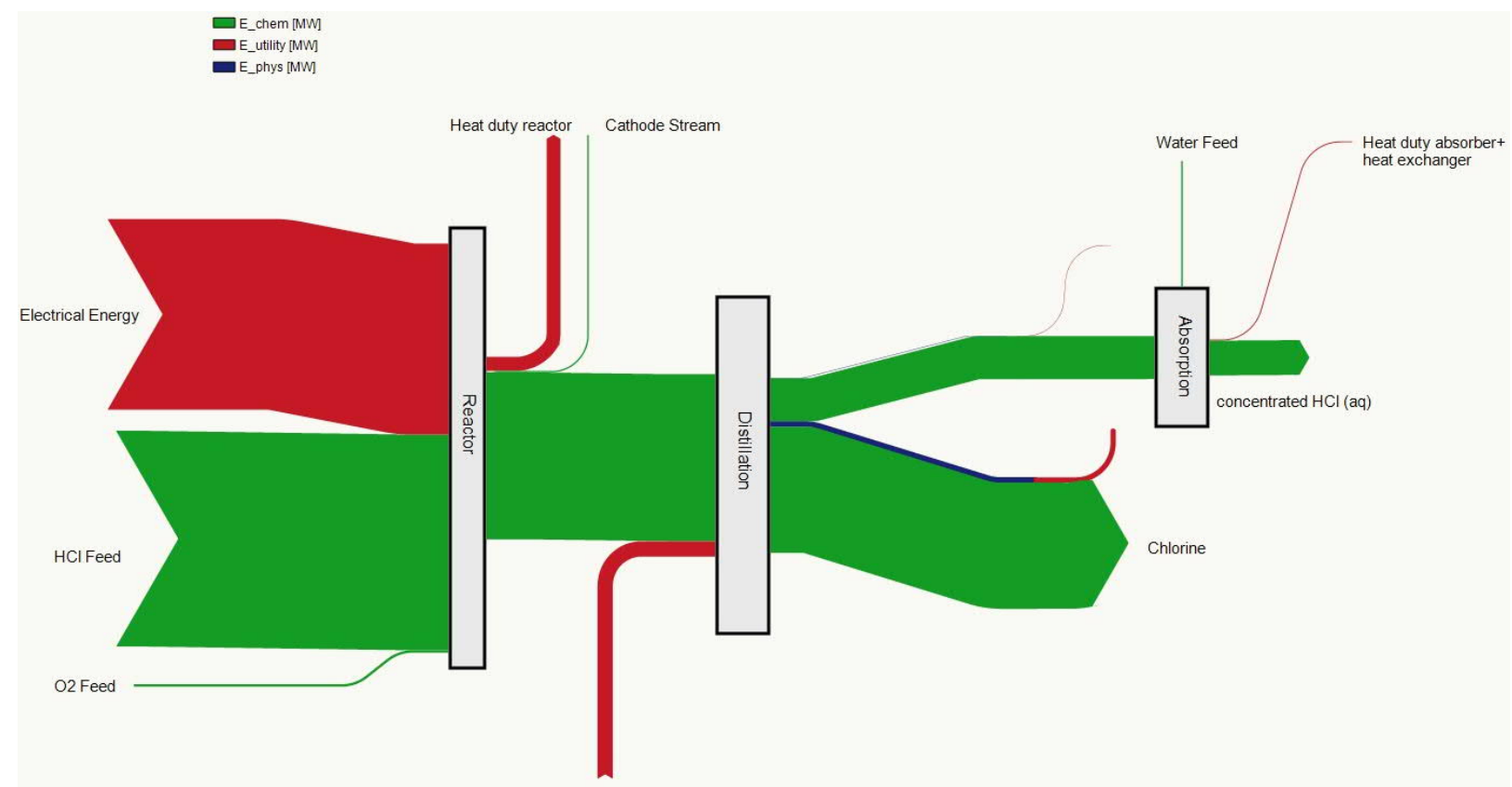

Fig. 8 Sankey diagram for the ELECTRA-DIST process with a single pass conversion of $80 \%$. The chemical and physical exergy flow of each stream is depicted in green and blue respectively, while the exergy flow of the incoming and outgoing heat and work streams is shown in red. The diagram visualizes the high relevance of the electrical energy input to the reactor unit in comparison to the relatively small heat duty of the distillation column. The physical exergy is negligible in all streams except for the liquid chlorine leaving at the bottom of the distillation column (blue line leaving the Distillation unit). Since the temperature of this stream is far below room temperature its vaporization leads to a noticeable exergy recovery.

If it is possible to operate the reactor at $80{ }^{\circ} \mathrm{C}$ instead of $40{ }^{\circ} \mathrm{C}$, the exergetic demand of the reactor unit will be further decreased by $18 \%$, since the exergetic proportion of the reaction heat increases with rising temperature. Additionally, this will also lead to a faster mass transfer and higher reaction rates which will enable the use of smaller reactors or higher current densities.

The reasons for the significantly lower heat duties in the distillation columns of the proposed novel process variants, compared to the state-of-the-art process, is the absence of water in the anode stream leaving the electrochemical reactor, which is very energy intensive to boil, and the higher achievable conversion in the electrochemical gas phase reactor which reduces the volume 
of the recycle streams. However, the column in the state-of-the-art process can be operated more efficiently compared to the one in the ELECTRA-DIST process. This is due to the column's molar reflux ratio which is an order of magnitude smaller. Since the condensers in all columns operate below ambient temperature, the heat released in the condenser leads to an increase of the exergy consumption. This increase in the reflux ratio is followed by higher condenser and reboiler duties which have a considerably negative effect on the exergetic efficiency of the distillation unit. Fig. 11 and 12 underscore this fact by showing a significant difference between the exergy contributions from the thermal discharge and the distillation column. At lower reflux ratios, a higher proportion of the exergy demand in the column can be regained through subsequent heat exchangers. In the ELECTRA-ABS process, the molar reflux ratio of the distillation column $R$ is smaller than 0.1 , however, due to the introduction of the auxiliary substance octane, the exergy demand of the column is comparable to the ELECTRA-DIST process. Nonetheless, due to the small reflux ratio a significant part, namely $59 \%$, of the exergy needed for distillation can be regained through heat exchangers subsequent to the column compared to only $37 \%$ in the ELECTRA-DIST process. Hence, even though the reactor clearly contributes most to the overall exergy demand, the distillation columns or alternative separation technologies should also be subject to further process intensification attempts.

Even though the exergy demand of the ELECTRA-DIST and ELECTRA-ABS process is very similar, there are distinct advantages of each variant of which some are given in the following. The former one for example, consists of fewer devices leading to lower investment cost. Additionally, changing the hydrogen chloride recycle ratio of the reactor will not affect the design parameters of the distillation column like the reflux ratio, the number of stages and the 
distillate-to-feed ratio as long as the single pass conversion does not change. If the recycle ratio is altered, only the throughput of the column has to be adjusted. Therefore, if a sufficient capacity factor for the column is considered, dynamically adjusting the process to a wider range of overall conversions of hydrogen chloride is possible. At higher recycle ratios, the reactor would only have to be operated at a higher potential in order to maintain the same conversion at shorter residence times induced by the higher flow rate resulting from the increased recycle ratio. This makes the ELECTRA-DIST configuration more suitable if the desired mass ratio of the chlorine and hydrochloric acid outlet streams undergoes changes for example due to different market situations. In the ELECTRA-ABS process, dynamically adjusting the overall conversion would be more complicated due to the interconnection of the absorption, extraction and distillation units.

However, the ELECTRA-ABS variant features major advantages, too. Firstly, while octane was chosen as extraction solvent in the current design, other alkanes - particularly heptane or hexane - could be suitable alternatives. With these solvents, Henry's constants for chlorine are increased leading to a lower selectivity and a higher necessary amount of organic solvent. However, the atmospheric boiling point of hexane is $68^{\circ} \mathrm{C}$ which would lead to a significant decrease in the heat duty of the distillation column, and hence the overall exergy demand. Therefore, systematic investigations using different solvents may reveal that the ELECTRA-ABS variant is even more efficient than the ELECTRA-DIST process. The separation steps in the ELECTRA-ABS process only contribute $7.4 \%$ to the overall exergy demand of the process. Hence, the potential for further process optimizations is significantly higher at the reactor level. However, as stated in chapter 2.4, choosing decane instead of octane as a solvent leads to an additional exergy demand 
of $0.8 \mathrm{MW}$ which is $3 \%$ of the exergy consumption of the overall process. Therefore, in addition to future investigations on reducing the electrical power consumption of the reactor, the ELECTRA-ABS process also holds further potential regarding the choice of the used solvent.

Secondly, the ELECTRA-ABS process is not prone to water traces contained in the anode gas stream of the electrochemical reactor that could arise from the water-crossover from the cathode compartment through the membrane to the anode side. This is due to the fact that in the extraction step, hydrogen chloride and water are separated from the octane stream containing chlorine. Small traces of water from the reactor can therefore not accumulate, since they are transferred into the aqueous phase during the extraction step. In the ELECTRA-DIST process however, the anode stream would have to be dried before entering the distillation column, since water would contaminate the chlorine product or react with the hydrogen chloride to form corrosive hydrochloric acid which would also contaminate the chlorine. This could be realized by cooling down the anode reactor outlet stream in order to condense the potentially present water. Since the subsequent distillation is carried out at low temperatures, which makes it necessary to cool down the $\mathrm{HCL} / \mathrm{CL}_{2}$ mixture, this condensing step would not significantly influence the exergy demand of the process.

Finally, the condenser temperature in the column of the ABS process is at $244-248 \mathrm{~K}$ compared to $187 \mathrm{~K}$ in the case of the ELECTRA-DIST process. Therefore, if the feed gas is not compressed in the ELECTRA-DIST variant, the condenser temperature is even too low for the utilization of an ammonia cooling cycle. As shown in the following, in order to reach a similar condenser temperature as in the ELECTRA-ABS process, the column feed would have to be 
compressed to a pressure of more than $10 \mathrm{bar}$ in the ELECTRA-DIST variant which would increase the overall exergy demand by $0.35 \mathrm{MW}$. Therefore, providing sufficient cooling for the distillation column is much easier and less cost intensive for the ELECTRA-ABS process, especially if the efficiency of generating an external supply of a cooling medium is considered.

Fig. 9 displays the additional overall exergy demand of the ELECTRA-DIST process and the condenser temperature as function of feed gas pressure of the column at $80 \%$ single pass conversion. It was assumed that the pressure in the column is identical with the feed pressure and constant on all stages. Since the boiling point of the gases increases with pressure, the condenser temperature is rising as well. At a pressure of 10 bars, the condenser temperature of the ELECTRA-DIST variant is at $240 \mathrm{~K}$, and hence is still lower than the temperature of 244 $248 \mathrm{~K}$ in the column of the ELECTRA-ABS process. The increased pressure leads to a lower exergy consumption of the distillation column. However, taking into consideration the power input of the compressor and the heat exchangers implemented in the process, the overall exergy demand rises with increasing pressure. Nevertheless, the additional exergy demand due to an elevated pressure of 10 bars is only $1.4 \%$ of the exergy required for the overall process. Therefore, taking into consideration the positive effect on the cooling effort, a moderate pressure between 2 and 10 bar is the most practical and feasible choice. 


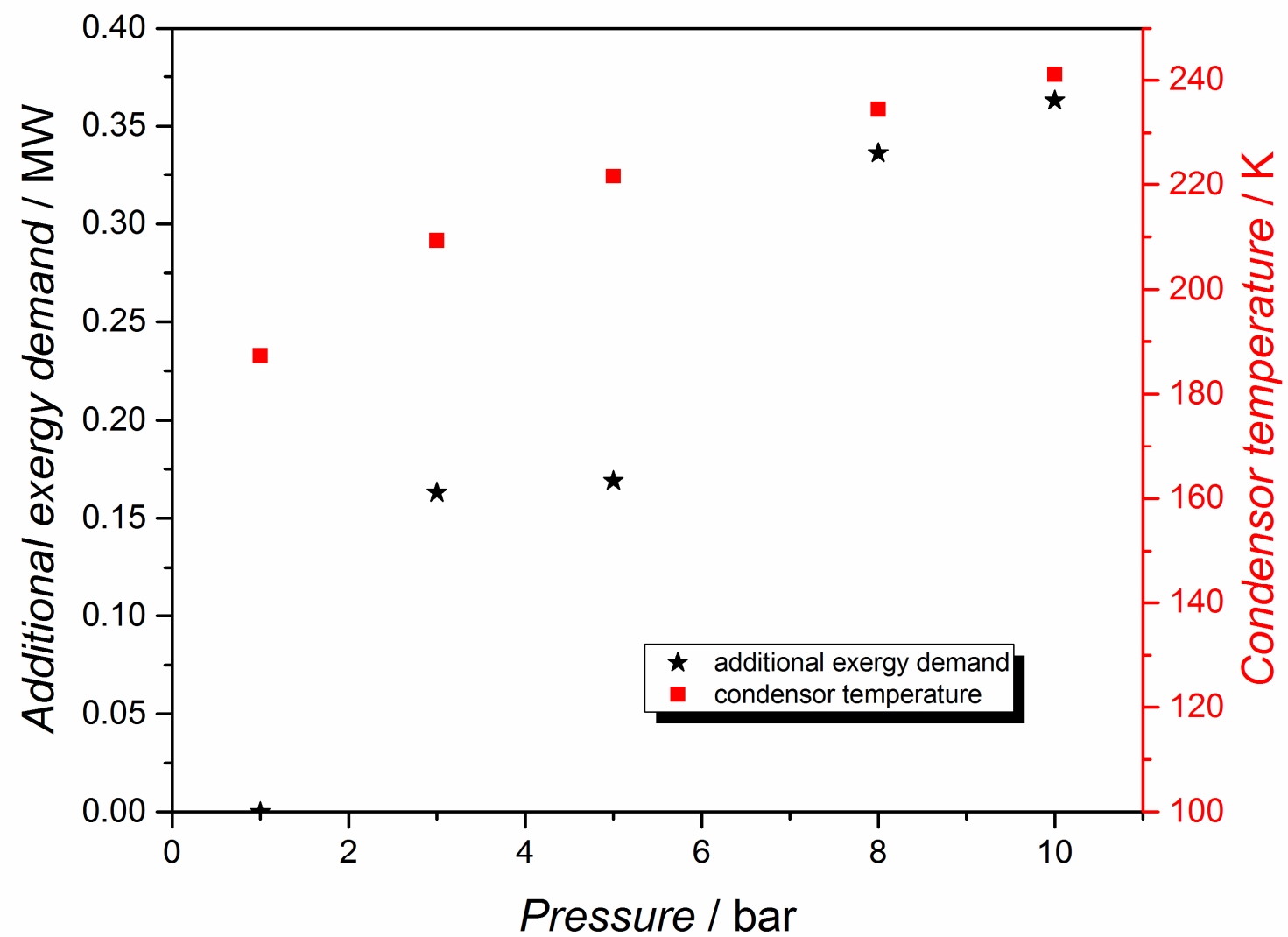

Fig. 9 Additional exergy demand and condenser temperature in dependence of the operating pressure of the distillation column in the ELECTRA-DIST process. The reflux ratio in the column was slightly adjusted with varying pressure in order to meet the specified purity of hydrogen chloride $(99.9 \mathrm{wt} \%)$ and chlorine $(99.5 \mathrm{wt} \%)$. Since the variation in the reflux ratio was lower than $5 \%$, the number of stages was kept constant at 16 for all pressure levels investigated.

\subsection{Influence of conversion on the exergetic efficiency and specific exergy demand}

Finally, the influence of the overall conversion on the specific total exergy demand per $\mathrm{kg}$ of chlorine was investigated for the novel ELECTRA-DIST and ELECTRA-ABS processes. The previous analysis showed that a recycle of hydrogen chloride leads to a slight increase of the overall exergy demand. Therefore, in the following, no hydrogen chloride recycle was 
implemented so that the overall conversion is equal to the single pass conversion in the reactor. Fig. 10 displays the specific exergy demand as well as the exergetic efficiency of ELECTRADIST and ELECTRA-ABS process. Hereby, the exergetic efficiency $\eta$ and the specific total exergy demand $b_{\text {spec }}$ are calculated as follows:

$$
\begin{gathered}
\eta=\frac{B_{C l_{2}, \text { chem }}}{B_{H_{2} O, \text { chem }}+B_{O_{2}, \text { chem }}+B_{H C l, \text { chem }}+\sum B_{\text {heat }}+\sum B_{\text {electrical }}} \\
b_{\text {spec }}=\frac{B_{H_{2} O, \text { chem }}+B_{O_{2}, \text { chem }}+B_{H C l, \text { chem }}-B_{C l_{2}, \text { chem }}-B_{H C l, \text { chem }}+\sum B_{\text {heat }}+\sum B_{\text {electrical }}}{\dot{m}_{C l_{2}}}
\end{gathered}
$$

In these equations $\dot{m}_{\mathrm{Cl}_{2}}$ stands for the mass flow of produced chlorine, and $\sum B_{\text {heat }}+$ $\sum B_{\text {electrical }}$ summarizes the exergies of all heat and work streams entering the system. Note that also the chemical exergy of input and output streams are incorporated into the exergetic efficiency and the specific exergy demand per $\mathrm{kg}$ of chlorine. Up to this point, only the exergy of the incoming and outgoing work and heat streams have been considered, since the chemical exergy has been constant in all cases due to the fixed overall conversion of $80 \%$. With a changing conversion however, the chemical exergy has to be considered as well. The hydrochloric acid that emerges as byproduct from unreacted hydrogen chloride in these processes has not been included into the calculation of the exergetic efficiency according to equation 20 for the following reason. If the exergy of hydrochloric acid was included, then zero conversion would be most efficient, since no electrical power would be needed, and since the Gibbs free reaction energy for dissolving all hydrogen chloride in water would be greater than for its oxidation to chlorine and water. Due to the fact that chlorine is the desired main product of 
this process, including the exergy of the hydrochloric acid stream would distort the meaning and purpose of the efficiency calculations.
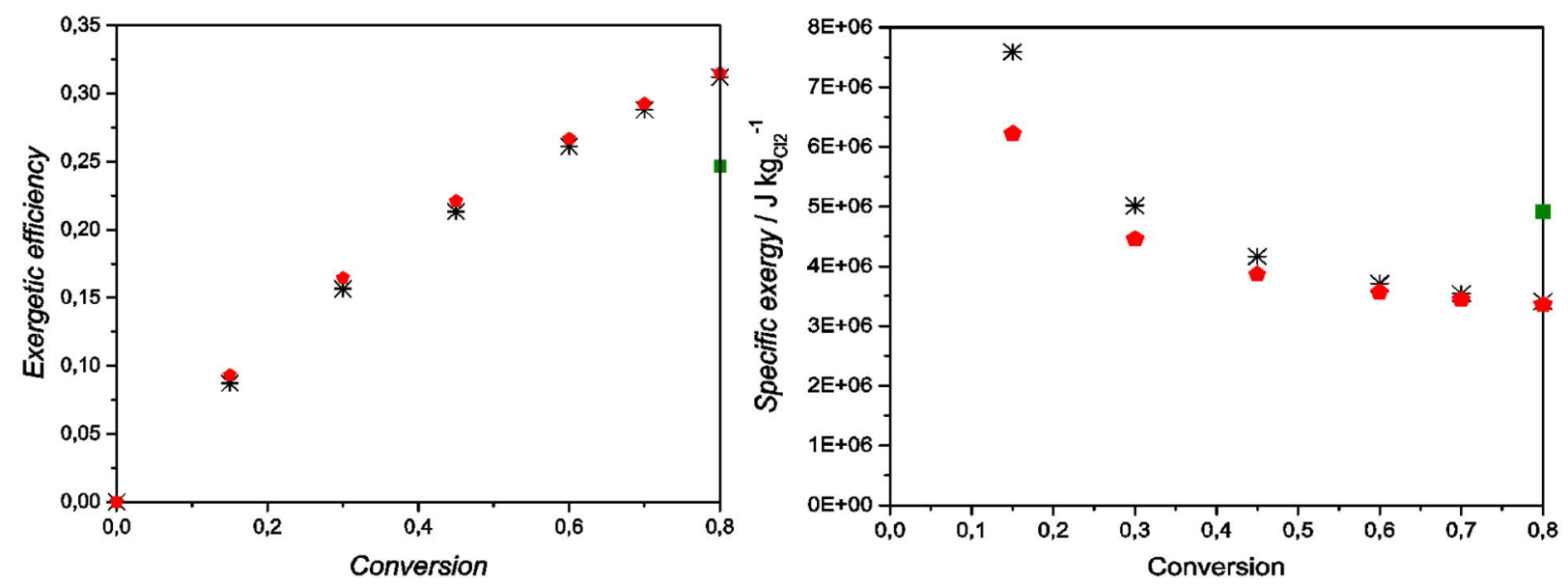

Fig. 10 Exergetic efficiency (left) and specific total exergy demand per kg of chlorine (right) for the ELECTRA-DIST process (red) and the ELECTRA-ABS process (black) as well as for the state-of-the-art liquid phase variant (green) in dependence of the $\mathrm{HCl}$ conversion. Note again that the single pass conversion in these specific cases is equivalent to the overall conversion, except for the single data point of the state-of-the-art process, which was simulated with a single pass conversion of $22.9 \%$ based on the literature discussed in chapter 2.2 and an overall conversion of $80 \%$.

Fig. 10 shows that the exergetic efficiencies of the ELECTRA-DIST and ELECTRA-ABS processes are very similar, especially at conversions higher than $30 \%$. At low conversions, the relative difference is becoming more significant, yet it is still below $7 \%$. The same correlation holds for the specific total exergy demand of chlorine. Thus, the diagram visualizes and quantifies the already discussed observation that the ELECTRA-DIST variant is becoming more efficient in comparison to the ELECTRA-ABS process at very low conversion. Additionally, for both variants, a plateau in the specific exergy demand in the right hand diagram is imminent at conversion degrees greater than $60 \%$. This means that increasing the conversion to values greater than $60 \%$ does not significantly reduce the exergy demand. Therefore, the novel proposed processes are already very efficient at medium conversions and there is no urgent need 
for a more technical challenging high conversion. Finally, Fig. 9 also contains the specific exergy demand and the exergetic efficiency of the state-of-the-art process and hereby illustrates the already discussed remarkable exergetic advantage of the novel process variants compared to the state-of-the-art liquid phase process.

\section{Conclusion}

The electrolysis of gaseous hydrogen chloride leads to a significant reduction of the exergy demand compared to the state-of-the-art liquid phase process, not only on the reactor unit level but also on the process level by $36 \%$ and $38 \%$, respectively. Moreover, only a slight difference was found for the two cases with a single pass reactor conversion of $60 \%$ and $80 \%$, showing that the novel processes are even feasible at moderate conversions. The overall exergy demand was broken down into contributions from the reactor, pressure changers, heat exchangers and the distillation column for all investigated processes. It can be concluded that the electrical energy consumption of the reactor plays by far the most important role in the overall exergy balance. Hence, in future process optimization attempts, further reducing the cell potential by means of systematic reactor optimization should be the major focus. Zhao et al. have suggested two alternative cathode reactions employing a $\mathrm{Fe}^{2+} / \mathrm{Fe}^{3+}$ and $\mathrm{I}_{3}^{-} / \mathrm{I}^{-}$redox mediation $[10,11]$. The respective reduced ion is oxidized, and thereby regenerated with the help of a gaseous oxygen feed into the catholyte tank. The advantage of this method is a low cell potential of $0.64 \mathrm{~V}$ for the $\mathrm{Fe}^{2+} / \mathrm{Fe}^{3+}$ pair and 0.94 for the $\mathrm{I}_{3}^{-} / \mathrm{I}^{-}$pair $\mathrm{V}$ at $4 \mathrm{kA} \mathrm{m}$. However, both cells have the significant disadvantage of a high decay rate. After an operation time of $80 \mathrm{~h}$ in the $\mathrm{Fe}^{2+} / \mathrm{Fe}^{3+}$ case and only $17 \mathrm{~h}$ in the $\mathrm{I}_{3}^{-} / \mathrm{I}^{-}$case, the cell potential increased to almost $1.2 \mathrm{~V}[10,11]$. This 
strong decay makes these two process variants unemployable for any industrial or long term application in their current state.

Another very decisive difference between the novel and the state-of-the-art process is its energyefficient separation strategy in comparison to the costly distillation applied in the Bayer UHDENORA process, due to the high heat capacity of water and enormous recycle streams in the Bayer UHDENORA process. Two separation methods have been proposed in this work, one based on the difference in the fugacities of the unreacted hydrogen chloride and the emerging chlorine and the other one based on differences in their solubilities in the solvent octane in combination with a subsequent extraction and desorption step. From an exergetic point of view, both variants are significantly more effective than the state-of-the-art liquid phase method and each of them possesses distinct advantages, allowing for the consideration of site-specific selection criteria when choosing one of the two process variants. Additionally, first investigations have been carried out regarding the influence of compressing the feed gas of the distillation column in the ELECTRA-DIST process on the overall exergy demand. While compressing the gas leads to a slight additional increase in the exergy demand, for practical reasons a pressure between 2-10 bar is still feasible due to a higher condenser temperature and therefore a reduced cooling effort. Finally, the influence of the overall conversion on the efficiency of the process and on the specific exergy demand per ton of chlorine has been investigated. While high conversion levels are most feasible from an exergetic point of view, the results indicate a plateau at conversion levels higher than $60 \%$. This supports the findings that also moderate conversions are exergetically beneficial and further underlines the significant ecological and economical potential of the novel proposed processes. 


\section{Acknowledgement}

The author Simon Bechtel is also affiliated to the International Max Planck Research School (IMPRS) for Advanced Methods in Process and Systems Engineering, Magdeburg, Germany.

\section{Declarations of interest}

None.

This research did not receive any specific grant from funding agencies in the public, commercial, or not-for-profit sectors.

\section{Literature}

1 Rohan. Chlorine Market by Application (EDC/ PVC, C1 \& C2 Aromatics, Inorganic Chemicals, Organic Chemicals, Chlorinated Intermediates, Isocyanates, Propylene Oxide, Pulp \& Paper, Textiles, Water Treatment, Others), by Region - Trends \& Forecasts to 2019 [Internet]. Seattle: MarketsandMarkets; 2015 [cited 2017 Nov 10]. Available from: https://issuu.com/jswapn23/docs/chlorine_market_worth

2 Euro Chlor [Internet]. Brussels: The European Chlor-Alkali industry: an electricity intensive sector exposed to carbon leakage; 2010 Dez. [cited 2017 Dez 22]. Available from: http://www.eurochlor.org/media/9385/3-2-the_european_chlor-alkali_industry__an_electricity_intensive_sector_exposed_to_carbon_leakage.pdf 
3 Sonnenschein MF. Polyurethanes Science, Technology, Markets and Trends. Hoboken: Wiley; 2015.

4 Martinez IG. Elektrolyse von Chlorwasserstoff in einem Polymerelektrolyt-Membranreaktor mit Sauerstoffverzehrkathode. $\mathrm{PhD}$ Thesis at the Otto von Guerricke Universität Magdeburg; 2015.

5 Perez-Ramirez J, Mondelli C, Schmidt T. Sustainable chlorine recycling via catalysed $\mathrm{HCl}$ oxidation: from fundamentals to implementation. Energy Environ Sci. 2011 Sep 30; 4:47864799.

6 Processing magazine [Internet]. Birmingham: Grand View Media Group. Global polycarbonate capacity to grow more than $5 \%$ by 2018; 2013 Nov 15 [cited 2017 June 28]. Available from: http://www.processingmagazine.com/global-polycarbonate-capacity-to-grow-more-than-5-by2018/

7 ThyssenKrupp Uhde GmbH. Dortmund: Hydrochloric acid electrolysis sustainable chlorine production. 2012 June

8 Merchant Research \& Consulting ltd. [Internet] Birmingham. TDI manufacturers in Europe restructure and expand their production capacities; 2015 May 5. [cited 2017 June 25] Available 
from: https://mcgroup.co.uk/news/20150505/tdi-manufacturers-europe-restructure-expandproduction-capacities.html

9 Motupally S, Becker AJ, Weidner JW. Water Transport in Polymer Electrolyte Membrane Electrolyzers Used to Recycle Anhydrous HCl. J Electrochem Soc. 2002; 149.

10 Zhao Y, Gu S, Gong K. Low-Voltage Gaseous HCl Electrolysis with an Iron Redox-Mediated Cathode for Chlorine Regeneration. Angew. Chem. Int. Ed. 2017; 56: 1-6

11 Zhao Y, Gu S, Gong K. Iodine Redox-Mediated Electrolysis for Energy-Efficient Chlorine Regeneration from Gaseous HCl. J. Electrochem. Soc. 2017; 164: E138-E143

12 Kuwertz R. Energy-efficient chlorine production by gas-phase hydrogen chloride electrolysis with oxygen depolarized cathode. PhD Thesis at TU-Clausthal, 2016

13 Goedecke R, Hofen W, Sass R, Wendeler H. Fluidverfahrenstechnik: Grundlagen, Methodik, Technik, Praxis. Weinheim: Wiley-VCH; 2011.

14 Marquardt W. Trends in computer-aided process modeling. Comput Chem Eng. 1996 Sep 10;20:591-609 
15 BASF Trade news [Internet]. Ludwigshafen: MDI capacity increases at BASF Verbund site in Antwerp, Belgium; 2017 Jan 23. [cited 2017 May 5]. Available from: https://www.basf.com/en/company/news-and-media/news-releases/2017/01/p-17-110.html

16 The Linde group [Internet]; Munich: Chlorine Grade 2.5; [cited 2017 May 8]. Available from: https://shop.lindecanada.com/shop/en/ca/specialty-gases/pure-gases/chlorine/chlorine-grade-25gv240639-131

17 Ooms P, Bulan A, inventors. Bayer Material Science AG, assignee. Verfahren zur Herstellung von Diarylcarbonaten und Polycarbonaten. EP 2371807 A1. 2010 March 30.

18 Trainham JA, Law CG, Newman JS, Keating KB, Eames DJ, inventors. Electrochemical conversion of anhydrous hydrogen halide to halogen gas using a cation-transporting membrane. US Patent US5411641 A. 1993 Nov 22.

19 Tremblay D, Watanasiri S, Song Y, Chen CC. Benefits of multi-solvent NRTL models in Aspen Plus [Internet]. Bedford: Aspentech, 2012 [cited 2017 June 1] Available from: https://www.google.de/url?sa=t\&rct=j\&q=\&esrc=s\&source=web\&cd=1\&ved=0ahUKEwjYpoX Mnd_XAhXDcBoKHbyUC5EQFggmMAA\&url=http\%3A\%2F\%2Faspentech.com\%2FWhitepa per\%2FBenefits-of-Multi-Solvent-NRTL-Models-in-AspenPlus.pdf\&usg=AOvVaw22AJObZMSbqlsrmLQJdEXd 
20 Morris JC. The mechanism of the hydrolysis of chlorine. J Am Chem Soc. 1946 Sep; 68: $1692-1694$

21 National Institute of Standards and Technology [Internet]. Gaithersburg. [cited 2017 May 5]. Available from: https://www.nist.gov/

22 Aspen Technology Inc. Bedford: Aspen physical property system. 11.1. 2001 Sep [cited 2017 Jun 5]. Available from:

http://web.ist.utl.pt/ist11061/de/ASPEN/Physical_Property_Data_Aspen.pdf

23 Carlson C. Don't gamble with physical properties for Simulations. Chem Eng Prog. 1996 Oct; $35-46$

24 Freire FJ, Kaiser BA, Felix VM, Mah DT, Trainham JA, Law CG, et al, inventors. Production of isocyanate using $\mathrm{HCl}$ recycle. US Patent US6010612 A. 1993 Nov 22.

25 Foster EG, inventor. Process for recovery of chlorine from hydrogen chloride. US Patent US4394367 A. 1982 March 11.

26 Gestermann F, Schneider J, Dummersdorf H. Verfahren zur Aufbereitung der Reaktionsgase bei der Oxidation von HCL zu Chlor. German Patent DE 19535716 A1. 1995 Sep 26. 
27 Ando H, Uchida Y, Kohei S, Knapp C, Omoto N, Kinoshita M. Trends and Views in the Development of Technologies for Chlorine Production from Hydrogen Chloride. Sumitomo Chemical Co. 2010; 2.

28 Fischer K, Horstmann S, Gardeler H. Predictive Soave-Redlich-Kwong equation of state (PSRK) [Internet]. Universität Oldenburg: 2004 Aug 26 [cited 2017 May 5]. Available from: http://www.gmehling.chemie.uni-oldenburg.de/9775.html

29 P\&I Design. Process modelling selection of thermodynamic methods [Internet]. Gladstone: Edwards JE; 2008 [cited 2017 Aug 4]. Available from: http://www.chemstations.com/content/documents/Technical_Articles/thermo.pdf

30 Young CL. Solubility data series, Sulfur dioxide, chlorine, fluorine and chlorine oxides [Internet]. Oxford: Pergamon Press; 1983 [cited May 3]. 496 p. Available from: https://www.elsevier.com/books/sulfur-dioxide-chlorine-fluorine-and-chlorineoxides/young/978-0-08-026218-5

31 Maczynski A, Goral M, Wisniewska-Goclowska B. Mutual solubilities of water and alkanes. Monatsh Chem 2003 March 13; 134: 633-653.

32 Lax E. Taschenbuch für Chemiker und Physiker Band 1: Makroskopische physikalischchemische Eigenschaften. Berlin Heidelberg: Springer-Verlag; 1967 
33 Alkan M. Solubility of chlorine in aqueous hydrochloric acid solutions. J Hazard Mater. 2005 March 17; A119: 13-18

34 Abdollahi-Demneh F, Moosavian MA, Omidkhah MR, Bahmanyar H. Calculating exergy flowsheeting simulators: A HYSIS implementation. Energy. 2011; 36: 5320-5327.

35 Gonzales-Regueral B, Querol E, Perez-Benedito JL. Practical approach to exergy and thermoeconomic analyses of industrial processes, London Springer; 2013. 84 p.

36 Wilhelm E, Batting R, Wilcock RJ. Low-Pressure Solubility of Gases in Liquid Water. 1977; 17: $219-262$

37 Szargut J. Exergy Method: Technical and Ecological Applications. 18th ed. Silesian University of Technology Poland: WIT Press Southampton UK; 2005. 192 p.

38 Kaiyuan Z, Hongyi L. Determination of mean activity coefficients of hydrochloric acid in concentrated solutions up to $15 \mathrm{~m}$ with glass electrode. Acta Physico-Chimica Sinica. 1986; 2: $30-36$.

\section{Supplemental information}

Based on the balance condition that the molar flux of chlorine entering the extraction, $\dot{n}_{\mathrm{Cl}_{2}}$, and the molar flux of chlorine in both streams leaving the extractor is equivalent, equation SI. 1 can be obtained as a solution: 


$$
\dot{n}_{C l_{2}, \text { water }}=-\frac{\dot{n}_{C l_{2}}(1-K)+\dot{n}_{\text {octane }}+K \dot{n}_{\text {water }}}{2(K-1)}+\sqrt{\frac{\left(-\frac{\left.\dot{n}_{C l_{2}(1-K)+\dot{n}_{\text {octane }}+K \dot{n}_{\text {water }}}\right)^{2}}{2(K-1)}+\frac{K \dot{n}_{\text {water }} \dot{n}_{C l_{2}}}{K-1}\right.}{4}}
$$

All streams and the according molar fluxes are visualized in Fig. 6 of the full article. Since the molar flux of chlorine that is transferred into the water phase is small, a simplified solution can be obtained that only differs by $0.5 \%$ from the above accurate solution at the present conditions:

$$
\dot{n}_{C l_{2}, \text { water }} \approx \frac{K \dot{n}_{\mathrm{Cl}_{2}} \dot{n}_{\text {water }}}{\dot{n}_{\text {octane }}+\dot{n}_{C l_{2}}}
$$

From the octane-water solubility data given earlier in this section follows for the water-rich phase:

$$
\frac{\dot{n}_{\text {water }, \text { water }}}{\dot{n}_{\text {octane,water }}}=\frac{x_{\text {water }, \text { water }}}{x_{\text {octane,water }}}=\frac{1-9,96 \times 10^{-8}}{9.96 \times 10^{-8}}=1.004 \times 10^{7}
$$

and for the octane-rich phase it can be concluded:

$$
\frac{\dot{n}_{\text {octane }, \text { oct }}}{\dot{n}_{\text {water, oct }}}=\frac{x_{\text {octane }, \text { oct }}}{x_{\text {water }, \text { oct }}}=\frac{1-5 \times 10^{-4}}{5 \times 10^{-4}}=1999
$$

If $\dot{n}_{\text {octane }}$ is the molar flux of octane entering the extraction, $\dot{n}_{\text {octane,water }}$ the molar flux of octane moving into the water phase and $\dot{n}_{\text {water,oct }}$ the molar flow of water transferred into the octane phase, the following equation can be formulated:

$$
\frac{\dot{n}_{\text {octane }}-\dot{n}_{\text {octane,water }}}{\dot{n}_{\text {water }, \text { oct }}}=1999
$$

In a similar manner for the molar flux of employed water, $\dot{n}_{w a t e r}$, the following equation can be obtained:

$$
\frac{\dot{n}_{\text {water }}-\dot{n}_{\text {water }, \text { oct }}}{\dot{n}_{\text {water }, \text { oct }}}=1.004 \times 10^{7}
$$

The amount of water and octane in each phase can be calculated from equations SI.5 and SI.6. 